\title{
El papel de los jueces en el marco de una carta de derechos: Una teoría de la contención judicial The Role of Courts under a Bill of Rights: A Theory of Judicial Restraint
}

\author{
Aileen Kavanagh $\left.{ }^{*}{ }^{* *}\right)$ \\ University of Oxford \\ aileen.kavanagh@law.ox.ac.uk
}

Recibido / received:25/07/2017

Aceptado / accepted:21/08/2017

DOI: https://doi.org/10.20318/eunomia.2017.3806

\section{Resumen}

Este trabajo tiene un doble objetivo. La primera parte ofrece una visión de conjunto del sistema de derechos configurado en el Reino Unido mediante la Human Rights Act de 1998, donde se trata de mostrar que, a pesar de haber sido descrito como un ejemplo destacado de la revisión judicial "débil" de constitucionalidad, el sistema británico muestra en realidad muchos rasgos de sutil fortaleza. En la segunda parte se toma como referencia la jurisprudencia de los tribunales británicos en el marco de dicha ley, con objeto de articular una teoría de la contención judicial. La conclusión es que, a la hora de determinar la fuerza o debilidad del poder judicial en un determinado sistema de revisión constitucional, necesitamos ir más allá de los mecanismos formales contenidos en los textos para analizar las doctrinas y los recursos que usan efectivamente los jueces cuando revisan la compatibilidad de la legislación con los derechos.

\section{Palabras clave}

Revisión judicial en materia de derechos humanos, revisión judicial "débil", supremacía judicial, contención judicial.

\begin{abstract}
The aim of this paper is twofold. First, it provides an overview of the system of the rights-based under the UK Human Rights Act 1998, trying to show that although it is often described as a leading exemplar of 'weak-form' constitutional review, in reality, the UK system displays many signs of subtle strength. Second, it adopts the decision making of the English courts under this bill of human rights to elaborate a theory of judicial restraint. The upshot is that when assessing any system of constitutional review in order to determine the strength or weakness of judicial power, we need to look beyond the formal textual mechanisms to explore the doctrines and devices judges use when reviewing legislation for compliance with rights.
\end{abstract}

\footnotetext{
* Este artículo encuentra su origen en dos trabajos previos (Kavanagh, 2010a y 2015a) que han sido objeto de revisión y reedición por parte de la autora para esta ocasión, incorporando unas nuevas conclusiones. En dicha labor ha contado con la colaboración del profesor Mariano C. Melero de la Torre que asimismo ha revisado la traducción.

${ }^{(*)}$ Traducción de Rubén García Higuera.
} 


\title{
Keywords \\ Rights-based judicial review, weak-form judicial review, judicial supremacy, judicial restraint.
}

\begin{abstract}
SUMARIO. 1. Introducción. 2. La Human Rights Act de 1998: forma y función. 2.1. La interpretación bajo la sec. 3 de la HRA. 2.2. De la interpretación a la declaración de incompatibilidad. 2.3. El efecto de la declaración de incompatibilidad. 3. El papel de los tribunales en la aplicación del derecho público. 3.1. El dilema de la contención judicial. 3.2. Un intento de definición. 3.3. Razones para la contención judicial. 3.4. La interacción entre razones de carácter sustantivo e institucional. 3.5. Contención e imagen pública. 3.6. Cortesía, confrontación y sinceridad. 4. Conclusión. 5. Bibliografía.
\end{abstract}

\section{Introducción}

Cuando en la academia se comenzó a apuntar que en el sistema de protección de derechos adoptado por Reino Unido, Canadá y Nueva Zelanda se vislumbraba un nuevo modelo de "constitucionalismo commonwealth" (Gardbaum, 2001), el único reclamo del modelo era que parecía dar a los poderes electos la "última palabra" acerca de si y/o cómo proteger los derechos. Sin embargo, como demuestra la experiencia acumulada en dichos sistemas, los parlamentos no han utilizado de manera significativa su potestad formal para invalidar decisiones judiciales (Kavanagh, 2009, pp. 322-324; Dixon, 2012, p. 488). En Canadá, la cláusula notwithstanding apenas ha sido invocada por el Gobierno Federal (Hiebert, 2006; Bateup, 2009) y el Parlamento británico nunca ha invalidado o rechazado abiertamente una declaración judicial de incompatibilidad. Tampoco se ha revocado o modificado una interpretación judicial realizada al amparo de la sección 3 , ni siquiera en aquellos casos en los que era manifiesto el desacuerdo político respecto a la decisión tomada por los tribunales (Crawford, 2014).

En este trabajo se pretende cumplir con dos objetivos que convergen en un solo argumento. En la primera parte se proporciona una visión de conjunto del sistema de protección de derechos establecido en el Reino Unido mediante la Human Rights Act de 1998. En dicha descripción se intenta mostrar que el sistema británico, observado en su funcionamiento efectivo, difícilmente puede calificarse como un sistema de revisión constitucional "débil". En general, la idea que sostengo es que deberíamos sospechar de cualquier tipología de derecho constitucional comparado que adopte como principal componente de análisis los canales formales para la resolución de desacuerdos entre el legislador y los tribunales. Es precisamente esta idea desde la que se elabora, en la segunda parte del trabajo, una teoría de la revisión judicial a partir del proceso real de toma de decisiones que emplean los tribunales británicos bajo la mencionada ley de derechos humanos. Según esta teoría, la revisión judicial substantiva de la proporcionalidad de las decisiones públicas debe complementarse necesariamente con un escrutinio de las razones institucionales que definen el grado apropiado de deferencia judicial hacía los poderes democráticamente elegidos. La tesis principal de esta teoría es que la auto-contención judicial es una de las formas en que los jueces pueden calibrar si su actividad respeta adecuadamente la competencia institucional y la legitimidad de los poderes electos, facilitando así la división del trabajo entre los diferentes poderes del estado.

\section{La Human Rights Act de 1998: forma y función}


Cuando la Human Rights Act fue aprobada en 1998, la principal preocupación a lo largo del arco político era encontrar la manera de permitir a los jueces hacer cumplir los estándares de derechos humanos a la vez que se preservaba la idea de soberanía parlamentaria (Klug, 2003; Klug, 2007, p. 703; Kavanagh, 2009, pp. 310-3). No había el deseo de otorgar a los tribunales el poder para derogar leyes que existe en el modelo norteamericano (Irvine, 2003; Lester, 2002; Feldman, 1999, p. 169). El reto consistía en encontrar una forma de proteger los derechos a la vez que se aseguraba que el parlamento tendría la "última palabra" a la hora determinar el contenido del derecho (Klug, 2003, p. 126). ¿Cómo podía lograrse esto? Los legisladores encontraron una innovadora "solución de compromiso" "que incorporaron a la estructura y diseño de la HRA $^{2}$.

La HRA contiene tres mecanismos pensados para mejorar la protección de los derechos humanos en la legislación ordinaria. Los dos primeros son facultades otorgadas a los jueces; el tercero es un mecanismo orientado al procedimiento parlamentario. Los poderes dados a los tribunales se encuentran vinculados. El primero es el deber de interpretación previsto en la Sección 3 de la HRA, donde se indica que: "hasta donde sea posible, la legislación principal y la subordinada deben leerse y aplicarse de un modo que sea compatible con los derechos del Convenio" ${ }^{3}$. No obstante, cuando un tribunal considere que una interpretación acorde con los derechos no es posible, se activa el segundo mecanismo de protección de derechos, esto es, la facultad de emitir una "declaración de incompatibilidad" prevista en la Sección 4. Es significativo que esta declaración "no afecta a la validez de la norma en cuestión, que continúa aplicándose y ejecutándose, ${ }^{4}$ y tampoco es vinculante para las partes del procedimiento en que tiene lugar ${ }^{5}$. No tiene efecto jurídico vinculante.

En relación con el impacto de la HRA en el procedimiento parlamentario, la Sección 19 de la HRA establece que, cuando se presenta un proyecto de ley en el Parlamento ${ }^{6}$, el Ministro debe realizar (a) una declaración señalando que tal medida es compatible con los derechos del Convenio ("declaración de compatibilidad"); o (b) en caso de no poder realizar esa declaración, afirmar que, a pesar de ello, el Gobierno desea que la Cámara de los Comunes continúe la tramitación del proyecto. La Sección 19 habilita específicamente al Gobierno para tramitar una ley incluso en los casos en que considere que ésta pudiera violar los derechos del Convenio, si bien le obliga a explicitar dichas intenciones durante la tramitación del proyecto en el Parlamento (Kavanagh, 2009, p. 12). Pese a que el Ministro proponente no tiene la obligación jurídica de argumentar la declaración de la Sección 19, ni de iniciar un debate parlamentario sobre la materia, se ha establecido la práctica de que el Gobierno proporcione un Memorándum en el que delinea sus argumentos sobre la compatibilidad (véase Hunt, 2007, p. 473). Los Ministros casi siempre realizan una declaración de compatibilidad positiva. La "declaración de incompatibilidad" solo se ha producido en una ocasión (en relación con el Proyecto de Ley de Comunicaciones en 2003) y dicha ley fue declarada después por el Tribunal Supremo del Reino Unido como compatible con los derechos del Convenio.

\footnotetext{
${ }^{1}$ Feldman (1999), p. 169; R. (Chester) v. Secretary of State for Justice, [2013] 3 W.L.R. 1076 (S.C.), par. 120 (Lord Sumption)

El texto completo de la ley puede consultarse en: http://www.legislation.gov.uk/ukpga/1998/42/contents (fecha de consulta 29/08/2017). Véase también Van Zyl Smit (2011).

${ }^{3}$ Human Rights Act 1998, c. 42, par. 3(1) (U.K.).

${ }^{4}$ Ibid., par. 4(6)(a).

${ }^{5}$ Ibid., par. 4(6)(b).

${ }^{6}$ Esta declaración debe realizarse antes de la Segunda Lectura del Proyecto de Ley, ibid., par. 19(1).
} 
En este breve esbozo se pueden identificar fácilmente algunas de las características que son relevantes para la distinción entre los sistemas de revisión de carácter fuerte y débil. En particular, el legislador británico tuvo una voluntad deliberada de no otorgar a los tribunales el poder de derogar leyes, por lo que el Parlamento está expresamente facultado para promulgar legislación que pudiera contravenir los derechos del Convenio. Por tanto, desde un punto de vista de diseño constitucional, la HRA parece encajar dentro de la tipología elaborada por Mark Tushnet como un ejemplo de "revisión judicial débil". Pasemos entonces a observar cómo dichas previsiones funcionan en la práctica, con la finalidad de evaluar la utilidad de dicha caracterización. En este punto, será esencial atender a si estos mecanismos logran satisfacer lo que a juicio de Tushnet es el principal objetivo de la "forma débil de revisión judicial", esto es, dar al poder legislativo la "última palabra" en las cuestiones que afectan a derechos humanos (Tushnet, 2006). Para ello, me centraré primero en las dos facultades otorgadas al poder judicial y en la respuesta política a las mismas, debido a que éste es el elemento principal en la distinción de Tushnet entre las formas fuerte y débil de revisión judicial. Por esta razón, no indagaré acerca de la práctica de la "revisión legislativa de derechos", que se lleva a cabo durante la tramitación legislativa en el Parlamento ${ }^{7}$, ni tampoco haré mención al importante trabajo que lleva a cabo la Comisión Mixta para los Derechos Humanos en el fomento de una creciente implicación del legislativo en la protección de los derechos ${ }^{8}$.

\subsection{La interpretación según la Sección 3 de la HRA}

La cuestión decisiva en relación con la Sección 3 de la HRA es cuán lejos pueden llegar los jueces a la hora de interpretar la compatibilidad de la legislación con los derechos del Convenio ${ }^{9}$. Las reglas de la sección 3 no proporcionan mucha orientación, ya que simplemente señalan que los tribunales deberían adoptar una lectura compatible con el Convenio "hasta donde sea posible". Los tribunales han realizado una interpretación extensiva de las facultades de la Sección 3 , que les ha permitido alterar el significado de preceptos que en otro caso parecerían claros. Para ello, han ideado un proceso de interpretación dividido en dos fases, que funciona de la siguiente forma ${ }^{10}$. El primer paso consiste en establecer si la legislación, entendida de modo ordinario, viola los derechos del Convenio. Si no lo hace, en este punto finalizaría el análisis. Sin embargo, si el tribunal considera que prima facie se infringen derechos del Convenio, entonces debe entrar a valorar si hubiera la posibilidad de realizar una interpretación "conforme" que, siguiendo las reglas de la Sección 3 de la HRA, eliminara o "sanara" la aparente incompatibilidad". En esta segunda fase, los tribunales han sostenido que la Sección 3 les faculta para "adoptar una interpretación que lingüísticamente pudiera parecer forzada. Entre las técnicas a usar se incluyen la no consideración de la literalidad del texto legal ["reading down of express language in a statute"] así como la inferencia de disposiciones no escritas ["reading in" o "implication of provisions"] ${ }^{12}$.

\footnotetext{
${ }^{7}$ Véase más en Hiebert (2012). En ocasiones esta táctica es calificada como "revisión política de derechos", ver Choudhry (2013).

${ }^{8}$ Para una visión general en este tema, ver Hunt (2010). Nótese que, a diferencia de Mark Tushnet, Stephen Gardbaum hace de la "revisión legislativa de derechos" uno de los componentes esenciales de lo que denomina "modelo commonwealth" de justicia constitucional, ver Gardbaum (2013).

9 El significado de "posible" en el apartado 1 de la Sección 3 de la Human Rights Act fue una de las mayores preocupaciones de los primeros estudiosos de la Ley, ver Kavanagh (2009), pp. 25-9.

${ }^{10}$ Ibid., pp. 23-4; Gearty (2002).

11 Para una descripción del proceso en dos etapas, ver Gearty (2002), 252; Kavanagh (2009), 23-4; R. v. A., [2002] 1 A.C. 45 (H.L.), par. 43 (U.K.); Sheldrake v. Director of Public Prosecutions, [2005] 1 A.C. 264 (H.L.), par. 27-8 (Lord Bingham) (U.K.).

${ }^{12}$ R. v. A., [2002] 1 A.C. 45 (H.L.), par. 44
} 
El ejemplo más ilustrativo en materia de interpretación según la Sección 3 es Ghaidan v. Mendoza ${ }^{13}$. Este caso trata sobre el derecho de un miembro de una pareja homosexual al arrendamiento contraído por su pareja fallecida, en base a la Rent Act de 1977. En dicha ley se garantizaba el derecho de sucesión del arrendatario por parte del "cónyuge sobreviviente", definiendo "cónyuge" como "aquella persona que cohabitaba con el arrendatario original como su marido o mujer"14. La cuestión versaba sobre si dicho precepto era aplicable a las parejas del mismo sexo. La Cámara de los Lores sostuvo que, entendido en un sentido ordinario, la Rent Act no era aplicable a las parejas del mismo sexo, por lo que violaba claramente los derechos que el señor Mendoza tenía según el Convenio ${ }^{15}$. La siguiente pregunta era si esta vulneración aparente o prima facie podía ser solventada por la vía de una interpretación de la Sección 3.1. Una mayoría de 4 a 1 en la Cámara de los Lores sostuvo que esto era posible. ¿Cómo lograrlo? El tribunal estableció que, aunque la literalidad de la ley parecía excluir a las parejas del mismo sexo, la "política social" subyacente a dicha ley pretendía asegurar el arrendamiento a las parejas que mantenían una relación amorosa estable, criterio que podía aplicarse igualmente a las parejas del mismo sexo. De esta forma, los tribunales utilizaron la Sección 3 para releer la Rent Act de un modo compatible con el Convenio, eliminando el potencial efecto discriminatorio para las parejas del mismo $\operatorname{sexo}^{16}$.

Todos los jueces estimaron que la obligación interpretativa recogida en la Sección 3.1 tenía un "alcance inusualmente amplio" ${ }^{17}$ y no se limitaba a resolver las ambigüedades de la legislación mediante una interpretación que fijara un significado compatible con la Convención ${ }^{18}$. Tras este importante caso, Lord Nicholls aclaró que

incluso si, construido según los principios básicos de la interpretación, el significado de la legislación no admitiese dudas, la sección 3 podría otorgar a la legislación otro significado... La Sección 3 puede requerir al tribunal que se aparte de la intención legislativa, esto es, que se aparte de la intención del Parlamento que promulgó la legislación... ${ }^{19}$

¿Qué herramientas pueden utilizar los tribunales para hacer que la legislación sea conforme a los derechos del Convenio? Lord Nicholls ha aportado alguna orientación al respecto:

La Sección 3 permite interpretar el lenguaje de forma restrictiva o expansiva. Pero va incluso más allá. La Sección 3 tiende además a demandar del tribunal que introduzca palabras que modifican el significado de la legislación promulgada, haciéndola conforme con el Convenio. Dicho de otro modo, la intención del Parlamento al promulgar la sección 3 era que, hasta un punto sólo limitado por lo que es "posible", un tribunal pudiera modificar el significado, y por ende el efecto, de la legislación primaria y secundaria ${ }^{20}$.

\footnotetext{
13 Ghaidan v. Mendoza, [2004] 2 A.C. 557 (H.L.) (U.K.). Para un análisis detallado del caso, véase Kavanagh (2009), capítulo 3.

${ }_{14}^{14}$ Rent Act 1977 , c. 42, par. 2(1), sch. 1.

${ }^{15}$ Ghaidan v. Mendoza, [2004] 2 A.C. 557 (H.L.), par. 24 (U.K.).

${ }^{16}$ Ibid., par. 35.

17 lbid., par. 30

18 Ibid., pars. 29-30 (Lord Nicholls), par. 44 (Lord Steyn), par. 119 (Lord Rodger), par. 67 (Lord Millett).

${ }^{19}$ Ibid., par. 29.

20 Ibid., par. 32. Para la consideración de la analogía entre la Sección 3 de la Human Rights Act y la obligación que tienen los tribunales, según el Tratado de la Comunidad Económica Europea, de interpretar la legislación nacional a la luz del texto y los objetivos de las Directivas comunitarias, ver Schaeffer (2005).
} 
A pesar de que este enfoque expansivo de la obligación interpretativa no está exento de críticas en la academia (Van Zyl Smit, 2011; Nicol, 2006), ha sido plenamente respaldado en los casos posteriores y hoy está bien asentado en la jurisprudencia. Como señaló con sencillez Lord Bingham en el caso R. (Al-Skeini) $v$. Secretary of State for Defence: "la sección 3 proporciona una importante herramienta que debe ser usada allá donde la modificación de la legislación sea posible y necesaria, con el objeto de evitar incompatibilidades entre los derechos protegidos en la Ley y los derechos del Convenio"21. En la actualidad no hay "ninguna duda" 22 de que la obligación interpretativa que contiene la Sección 3 es "muy fuerte y de largo alcance, y puede demandar al tribunal que se aleje de la intención legislativa del Parlamento"23.

Amparados en la Sección 3, los tribunales han realizado interpretaciones audaces y creativas. Se han dado casos donde los tribunales han utilizado la Sección 3 para descartar palabras (read down) en aquellas disposiciones que claramente imponían al acusado una carga de la prueba "persuasiva" (es decir, más allá de toda duda razonable), con objeto de que significaran que el acusado sólo tenía la obligación de presentar una carga "probatoria" (evidential burden, es decir, suficiente para poner en cuestión la presunción de culpabilidad) ${ }^{24}$. En R. (Hammond) v. Home Secretary ${ }^{25}$, la Cámara de los Lores entendió que en la disposición normativa donde se establecía que la determinación de la duración mínima de las condenas a cadena perpetua "debe determinarse por un solo juez del Tribunal Superior sin vista oral", se daba al juez la posibilidad discrecional de celebrar vista oral cuando así lo exigiera el principio de imparcialidad, con objeto de hacer esta disposición compatible con el derecho a un juicio justo ${ }^{26}$. En el caso más controvertido de los resueltos por la Cámara de los Lores durante los primeros años de vigencia de la HRA $(R \vee . A)^{27}$, el tribunal sostuvo que una disposición promulgada por el Parlamento el año anterior, ${ }^{28}$ que pretendía proteger a las víctimas de violación limitando severamente la discrecionalidad judicial a la hora de admitir la historia sexual del querellante como prueba en el proceso judicial (incluyendo la historia sexual con el acusado), vulneraba el derecho del acusado a un juicio justo. Pese a que la disposición normativa era sumamente detallada y claramente excluía la admisibilidad de dicha prueba (de hecho, fue precisamente promulgaba para limitar la discreción judicial en tales casos) ${ }^{29}$, el tribunal infirió una subsección entera dentro de la Ley, con el fin de otorgar a los jueces la discreción para decidir si tales elementos probatorios eran o no "relevantes para valorar el consentimiento, de modo que al excluirse, se estaría poniendo en peligro la imparcialidad del proceso protegida por el Artículo 6 del Convenio"30. Aunque "lingüísticamente forzada", esta inferencia de disposiciones se consideró aceptable a la luz de la Sección 3, en gran medida con objeto de garantizar al acusado el derecho a un juicio justo ${ }^{31}$.

\footnotetext{
${ }^{21}$ R. (Al-Skeini) v. Secretary of State for Defence, [2008] 1 A.C. 153 (H.L.), par. 15 (U.K.).

${ }^{22}$ Sheldrake v. Director of Public Prosecutions, [2005] 1 A.C. 264 (H.L.), par. 28 (Lord Bingham).

23 lbid.

${ }^{24}$ Véase, por ejemplo, R. v. Lambert, [2002] 2 A.C. 545 (H.L.), par. 22 (U.K.). En este caso, el Tribunal entendió que la palabra "probar" en la Sección 28(2) de la Misuse of Drugs Act, de 1971, c. 38 (U.K.), significaba "dar suficientes indicios".

${ }^{25}$ R. (Hammond) v. Home Secretary, [2005] U.K.H.L. 69.

${ }^{26}$ Criminal Justice Act, 2003, apéndice 22, par. 1.

${ }^{27} R$ v. A, [2002] 1 A.C. 45 (H.L.) (U.K.). Para un análisis de este y otros casos resueltos durante los primeros años, véase Kavanagh (2009), ch. 2. Ver también Kavanagh (2005).

${ }^{28}$ Youth Justice and Criminal Evidence Act, 1999, c. 23 (U.K.).

${ }^{29}$ Ibid., par. 41.

30 El "test de admisibilidad" completo que fue incluido en la Sección 41 de la ley, está fijado en el párrafo 46; ver también Kavanagh (2009), 21.

${ }^{31}$ Para otro caso (más reciente) de inferencia, véase R. v. Waya, [2012] U.K.S.C. 51 (U.K.).
} 
Con carácter preliminar, varias cuestiones pueden señalarse sobre la naturaleza del deber interpretativo de la Sección 3. La primera consideración es que, con independencia de lo que digamos ulteriormente sobre él, no parece que sea adecuado describirlo como "débil". En la forma en que ha sido interpretado por los tribunales británicos, se ha entendido como una "exigencia fuerte" ${ }^{32}$ de interpretar la legislación en un sentido compatible con los derechos del Convenio, incluso aunque esto signifique ir en contra tanto del sentido inequívoco de la literalidad de la ley como de su intención. La dinámica del enfoque en dos fases muestra que la Sección 3 sólo se aplica cuando hay, prima facie, una vulneración de los derechos del Convenio (Gearty, 2002). Por ello, la cuestión en la segunda fase es si se puede (a pesar del juicio inicial en contrario) convertir una disposición en "compatible con el Convenio"33, utilizando las técnicas interpretativas. Los tribunales evalúan qué pueden hacer para "solventar la incompatibilidad" ${ }^{34}$ existente, ya sea eliminando o añadiendo palabras en la ley ${ }^{35}$. De hecho, es tal la fuerza con que los jueces han usado la Sec. 3 que ésta ha sido acusada de ser indistinguible de la enmienda legislativa (Nicol, 2004; sin embargo, véase Kavanagh, 2004).

En segundo lugar, recordemos que, al delinear su distinción entre formas fuertes y débiles de revisión judicial, Tushnet califica la interpretación compatible con los derechos como "la variante más débil de la revisión judicial débil" (Tushnet, 2003 , p. $820 ; 2008$, p. 28). La revisión judicial débil permite a los tribunales "interpretar, pero no reemplazar la legislación" (Tushnet 2003, p. 821; cfr. Kavanagh, 2004). Sin embargo, esta afirmación subestima el alcance que tienen ciertas formas de interpretación legislativa, que pueden llegar a "reemplazar" o, al menos, modificar preceptos legales inequívocos. Ciertamente, en la interpretación transformativa de la Sección 3 parece que se reemplazan disposiciones legales inequívocas por interpretaciones compatibles con los derechos elaboradas por el propio tribunal. De hecho, se podría sostener que, al menos en algunos casos, la Sección 3 permite a los tribunales británicos una forma más fuerte de sustitución que el que normalmente tienen los tribunales en los sistemas con competencias "derogatorias". Al fin y al cabo, "derogar" ["striking down"] es una metáfora para indicar que los tribunales declaran que la normativa vulnera derechos, y tiene el efecto de anular o declarar inaplicables las disposiciones en cuestión (Macklem, 2006). Cuando esto ocurre, el legislativo tiene la capacidad de decidir la forma en que enmienda la legislación con el fin de rectificar la vulneración de derechos, o si se olvida de dicha normativa por completo ${ }^{36}$. Sin embargo, cuando un tribunal del Reino Unido realiza una interpretación siguiendo la Sección 3 , no se limita meramente a la labor negativa de identificar que existe una vulneración de derechos. Va un paso (positivo) más allá, implementando una acción correctora que repara la violación, para lo cual utiliza diferentes técnicas interpretativas, como la inclusión y la exclusión de palabras, así como "la inferencia de disposiciones".

Además, es difícil valorar si el hecho de que los jueces reescriban o rectifiquen las leyes con objeto de "subsanarlas" o de evitar que interfieran con los derechos, es más o menos controvertido, desde un punto de vista democrático, que el hecho de que invaliden la legislación (Schauer, 1995, p. 95). Al menos la derogación da al legislativo la oportunidad de decidir qué hacer para corregir la

\footnotetext{
${ }^{32}$ R. v. Director of Public Prosecutions, ex parte Kebilene, [1999] 4 All E.R. 801 (H.L.) (U.K.).

${ }^{33}$ Principal Reporter v. K, [2010] U.K.S.C. 56, par. 66 (U.K.).

${ }^{34}$ Ibid., pars. 66 y 69.

${ }^{35}$ Secretary of State for the Home Department v. M.B., [2008] 1 A.C. 440 (H.L.), par. 4 (Lord Bingham) (U.K.); R. (Anderson) v. Secretary of State for the Home Department, [2002] 3 W.L.R. 1800 (H.L.), par. 58 (Lord Steyn) (U.K.).

${ }^{36}$ Una derogación crea un deber negativo, que prohíbe algo en particular, pero que permite otras opciones. Véase Macklem (2006), p. 123.
} 
vulneración de derechos, invitando así a una mayor colaboración e implicación por parte de los otros poderes que mediante la interpretación rectificativa. De hecho, en numerosas jurisdicciones con facultad derogatoria, los jueces a veces suspenden el efecto de la anulación con el fin de dar al legislativo el tiempo suficiente para adaptar la normativa a la resolución judicial a través de la medida que consideren más apropiada $^{37}$. Esto amplía el margen de maniobra del legislativo a la hora de decidir cómo confeccionar la disposición correctora.

Por el contrario, cuando son los propios jueces los que corrigen la ley siguiendo la previsión de la Sección 3 , son ellos quienes efectivamente se encargan de una especie de reconstrucción de la legislación, que corrige la vulneración de derechos con efecto inmediato (Sales \& Ekins, 2011, pp. 230-1; Mashaw, 1997, p. 105). Esta es una forma de enmienda por parte del poder judicial que conlleva cierta sustitución de la voluntad del parlamento (Schauer, 1995, pp. 94-5). En muchos casos, además, la sustitución tiene un carácter definitivo, ya que el parlamento carga con una inercia legislativa que dificulta su posible voluntad de invalidar una interpretación según la Sección $3^{38}$. De hecho, el Parlamento de Westminster nunca ha vencido esa inercia promulgando una disposición que dejara sin efecto o modificara una interpretación de la Sección 3 llevada a cabo por los tribunales superiores (para más información, véase Crawford, 2014). En consecuencia, si el rasgo característico de un sistema de revisión judicial débil es la relativa facilidad con que el legislativo puede responder a las decisiones judiciales en materia de derechos, este tipo de revisión no ha sido puesto en práctica en el Reino Unido, al menos en relación con las interpretaciones amparadas en la Sección 3.

\subsection{De la interpretación a la declaración}

Pasemos ahora a la declaración incompatibilidad, que normalmente se califica como uno de los elementos más innovadores del diseño previsto en la HRA. El primer punto a destacar sobre la declaración de incompatibilidad es que va inextricablemente unida al mandato de interpretación de la Sección 3. Esto es debido a que los tribunales solo pueden emitir la declaración "cuando la interpretación no pueda resolver la incompatibilidad"39. Por tanto, los límites de la Sección 3 provocan la declaración de la Sección 4. La HRA no especifica cuáles son dichos límites. Así, queda al criterio de los tribunales el fundamentar de forma razonada por qué consideran que no es posible realizar una interpretación conforme.

En el caso Ghaidan, la Cámara de los Lores señaló dos límites principales. El primero es que "los tribunales deben adoptar un significado que no sea contradictorio con elementos fundamentales de la legislación". El segundo es que los tribunales no realizaran pronunciamientos "para los que no estén capacitados. Puede haber diversas formas de hacer que una disposición sea conforme con el Convenio y la elección entre las mismas puede afectar a cuestiones que demandan deliberación del legislativo"40. Podemos calificar estas limitaciones como el límite de los "rasgos fundamentales" y el límite de la "deliberación legislativa", respectivamente (Kavanagh, 2009, p. 88). Ambos indican que, incluso cuando es posible para los tribunales incluir o excluir palabras usando la Sección 3 , no se debe

\footnotetext{
${ }^{37}$ Para una investigación sobre este fenómeno en Canadá, ver Choudhry y Roach (2003), p. 211; y Leckey (2015), cap. 5. En Irlanda, ver Carolan (2011).

${ }^{38}$ Para una discusión acerca de las diferentes inercias entre la Sección 3 y 4 de la Human Rights Act, véase Bateup (2009) p. 569; Choudhry (2013) 1099; Kahana (2002), pp. 250-251; Chandrachud, (2014).

${ }^{39}$ R. (Morris) v. Westminster City Council, [2005] E.W.C.A. Civ. 1184 (C.A.), para. 56 (Sedley LJ) (U.K.); Wilson v. First County Trust, [2003] U.K.H.L. 40, para. 14 (U.K.).

${ }^{40}$ Ghaidan v. Godin-Mendoza, [2004] U.K.H.L. 30, para. 33 (U.K.).
} 
contravenir "por completo la esencia" ${ }^{41}$ de la legislación que está siendo interpretada ${ }^{42}$. Allí donde la interpretación compatible con los derechos causara demasiada discordancia con el programa legislativo o requiriera de una reforma legal integral, los tribunales se inclinarán por dictar una declaración de incompatibilidad, dejando al parlamento la labor de corregir la vulneración de derechos $^{43}$

En general, los tribunales se han "abstenido de intentar formular reglas precisas" ${ }^{\prime 4}$ acerca de cuándo se han sobrepasado los límites de la Sección 3, pero sí han expresado su confianza en que, en la práctica, tales casos serían "bastante fáciles de identificar" ${ }^{\prime \prime 5}$. Bellinger $c$. Bellinger ${ }^{46}$ proporciona un buen ejemplo sobre las causas que pueden llevar a un tribunal británico a dictar una declaración de incompatibilidad, en vez de corregir por sí mismo la vulneración a través de la Sección 3. Según la señora Bellinger, una transexual que había cambiado su sexo de hombre a mujer, la Matrimonial Causes Act de 1973 violaba su derecho a la vida familiar y era discriminatoria al permitir casarse únicamente al "hombre" y a la "mujer" (con el género determinado por el nacimiento). La Cámara de los Lores aceptó que, entendida en sentido ordinario, la Ley de 1973 vulneraba los derechos del Convenio de la señora Bellinger. No obstante, a pesar de que hubiera sido sencillo el inferir la inclusión de los transexuales en la Ley de 1973 (Bateup, 2009; Kavanagh, 2009, p. 120; Phillipson, 2007; Hickman, 2010), y así corregir la vulneración de derechos con carácter inmediato, la Cámara declinó esa opción. Al decidir dictar una declaración de incompatibilidad, los jueces argumentaron que dar a "masculino" y "femenino" un significado más amplio

... plantearía asuntos cuya solución demanda un estudio en profundidad y un amplio proceso de consulta y debate en la opinión pública. Se plantean cuestiones de política social y de viabilidad administrativa en algunos puntos, y su interacción debe ser evaluada y equilibrada. No es adecuado que estas cuestiones sean determinadas a través de un proceso judicial. Son materias propias del Parlamento ${ }^{47}$.

En este caso se trataba de un asunto que "demandaba una reforma legislativa comprehensiva y no un desarrollo judicial por partes" ${ }^{\prime 4}$. Por lo tanto, la declaración de incompatibilidad era la solución más apropiada.

Se pueden apuntar una serie de cuestiones acerca de la interacción entre la Sección 3 y la Sección 4 . La primera es que la elección entre la rectificación judicial de una normativa incompatible por la vía de la Sección 3 y la declaración de incompatibilidad prevista en la Sección 4 depende del contexto y está muy influenciada por la preocupación reparadora del tribunal (Van Zyl Smit, 2011; Kavanagh, 2009, p. 123; Dixon, 2009). Si el tribunal cree que puede corregir una vulneración de derechos por la vía interpretativa de la Sección 3 (haciendo justicia para con el litigante individual), sin causar una excesiva discordancia en el marco legislativo en cuestión ni otros efectos colaterales negativos, entonces optará por la Sección 3 (Dixon, 2009; Choudhry y Roach, 2003, p. 243). En cambio, si fuera

\footnotetext{
${ }^{41}$ Ghaidan v. Godin-Mendoza, [2004] U.K.H.L. 30, para. 111 (Lord Rodger) (U.K.).

42 Ibid., para. 33 (Lord Nicholls).

${ }^{43}$ Véase más en Kavanagh (2004), pp. 270-274, 279-282. Sobre el "dilema de la reforma parcial", ver Raz (1979), cap. 10.

44 Ghaidan v. Godin-Mendoza, [2004] U.K.H.L. 30, para. 50; Sheldrake v. Director of Public Prosecutions, [2005] 1 A.C. 264 (H.L.), para. 28 (U.K.); R. v. Waya, [2012] U.K.S.C. 51, para. 14 (U.K.).

${ }^{45}$ Ghaidan v. Godin-Mendoza, [2004] U.K.H.L. 30, para. 50

${ }^{46}$ Bellinger v. Bellinger, [2003] 2 A.C. 467 (H.L.) (U.K.).

${ }^{47}$ Bellinger v. Bellinger, [2003] 2 A.C. 467 (H.L.), para. 37 (U.K.).

${ }^{48}$ Chief Constable of West Yorkshire Police v. A., [2005] 1 A.C. 51 (H.L.), para. 12 (U.K.); Kavanagh (2009), pp. 137-142.
} 
necesaria la reforma integral de un área completa y el tribunal creyera que no tiene ni suficientes competencias ni legitimidad para resolver el problema, entonces se inclinará por la declaración de la Sección $4^{49}$. Como señaló Lord Bingham extrajudicialmente, a la hora de elegir entre la Sección 3 y la Sección 4, un tribunal debe evaluar

si, enfrentados a una incompatibilidad, el Gobierno y el Parlamento contarían con medios más efectivos, desde un punto de vista práctico, para corregir la vulneración y, en su caso, si deberían tener la oportunidad de encontrar la mejor solución; si no, la Sección 3 proporciona la solución más inmediata y definitiva (Bingham, 2010, p. 572).

En segundo lugar, los tribunales británicos han formulado el principio general de que la Sección 3 debe tratarse como el remedio principal dentro de la Ley de Derechos Humanos, mientras que la declaración de incompatibilidad sólo debe usarse como último recurso ${ }^{50}$. Este es un principio que hoy en día se encuentra asentado en la jurisprudencia ${ }^{51}$. Como el Tribunal Supremo británico ha sostenido en numerosas ocasiones: "la sección 3(1) es el remedio principal y el recurso a la declaración de incompatibilidad debe tener siempre un carácter excepcional" ${ }^{52}$. ¿Por qué los tribunales han dado prioridad a la sección 3 de esta manera? Una de las razones podría ser el hecho de que, al tiempo que el debate del proyecto de ley de derechos humanos estaba teniendo lugar en el Parlamento, los Ministros del Gobierno expresaron la opinión de que los jueces deberían ser capaces de realizar una interpretación compatible con el Convenio "en casi todos los casos" ${ }^{\text {. }}$. La principal razón, sin embargo, es que solo una interpretación de la Sección 3 puede dar una solución al litigante individual. Irónicamente, es la vacuidad reparadora de la declaración de incompatibilidad lo que orienta a los tribunales del Reino Unido a adoptar interpretaciones altamente creativas e intervencionistas, que buscan llenar el vacío y corregir la situación. En algunas de las subsanaciones más controvertidas por la vía de la Sección 3, los tribunales estuvieron claramente motivados por la preocupación de que la legislación que siguiera a la declaración de incompatibilidad fuera a dejar desprotegidos a los litigantes individuales, causando una injusticia grave. Así, en un caso que versaba sobre el derecho a un juicio justo en un caso de violación, el tribunal re-escribió de modo substancial las disposiciones legales en cuestión, debido a que, en caso contrario, el acusado hubiera podido sufrir un juicio injusto. ${ }^{54}$ En este caso individual, el precio a pagar por subsanar una potencial injusticia fue un cierto grado de distorsión de la ley. De este modo, el hecho de que la declaración de incompatibilidad no tenga un efecto legal inmediato puede suponer un fuerte incentivo para que los tribunales británicos adopten interpretaciones legales más atrevidas y creativas de lo que sería la regla general en los sistemas en los que los tribunales tienen el poder de

\footnotetext{
${ }^{49}$ Rosalind Dixon ha defendido que la dimensión reparadora distorsiona la jurisprudencia, dado que los tribunales tienen un fuerte incentivo para adoptar una interpretación de la Sección 3 en los casos de derecho civil o penal, pero se sentirán más liberados para dictar una declaración de incompatibilidad en los "casos puros de derecho público", donde el problema de la reparación no es tan apremiante o inmediato, ver Dixon (2009); véase también Davis y Mead (2014).

${ }^{50}$ Ghaidan v. Godin-Mendoza, [2004] U.K.H.L. 30, para. 46 (U.K.).

51 Sheldrake v. Director of Public Prosecutions, [2005] 1 A.C. 264 (H.L.), para. 28; R. v. Waya, [2012] U.K.S.C. 51 , para. 14.

${ }^{52}$ R v. A, [2002] 1 A.C. 45 (H.L.), para. 44 (Lord Steyn).

${ }^{53}$ H.L. Debates, Feb. 5, 1998, col. 840 (tercera lectura) and H.C. Debates, Feb. 16, 1998, col. 778 (segunda lectura).

${ }^{54}$ Ver, p. ej., R v. A, [2002] 1 A.C. 45 (H.L.) (U.K.). Sobre la idea de que las consideraciones acerca de la reparación son un factor elemental en este caso, ver Kavanagh (2009), p. 33; Dixon (2009), pp. 345346.
} 
anular la legislación ${ }^{55}$.

Hay otro aspecto que merece ser mencionado y que está directamente relacionado con la distinción entre las formas fuerte y débil de revisión judicial. En el modo en que Tushnet y otros académicos lo presentan, la característica distintiva más atractiva de los sistemas de revisión judicial débil (y su principal ventaja frente a los sistemas fuertes) es que se da al legislativo la "última palabra" sobre cuestiones relacionadas con derechos. La experiencia de la HRA en el Reino Unido muestra que, con frecuencia, el gobierno no desea tener la última palabra y está feliz dejando que los tribunales tomen las decisiones en esos asuntos, liberando así al gobierno de la carga de corregir el problema. En este sentido, los abogados del Estado británico suelen argüir que, en los casos en los que se impugna la legislación ordinaria invocando la Ley de derechos humanos, los tribunales deberían corregir las vulneraciones de derechos por vía de la Sección 3, en vez de pronunciar una declaración de incompatibilidad ${ }^{56}$. Sobre esta práctica, Lord Phillips ha señalado que, en su experiencia judicial, el uso atrevido y creativo de la Sección 3 ha venido muy bien al Gobierno.

A los Ministros no les gustan las declaraciones de incompatibilidad. Siempre que no se perjudique el objetivo principal de su legislación, se muestran encantados de que los tribunales revisen la legislación para hacerla conforme con el Convenio antes de que la declaren incompatible. En mi experiencia, el abogado del Estado normalmente invita a los tribunales a interpretar de manera laxa, por muy complicado que sea, antes que realizar una declaración de incompatibilidad (Phillips, 2010).

¿Por qué los gobiernos suelen abogar por una interpretación de la Sección 3 y dejan a los tribunales que hagan el trabajo en derechos humanos por ellos? ¿Por qué no se apresuran a tomar la "última palabra" en cuestiones de tal importancia, tal y como muchos teóricos del derecho constitucional piensan que deberían hacer? Una posibilidad es que el gobierno no quiera asumir el coste político asociado a los titulares condenatorios que conlleva una declaración de incompatibilidad, y que por eso prefiera que los tribunales modifiquen la ley a través del proceso relativamente invisible de la interpretación judicial (Nicol, 2004, p. 468; Hiebert, 2012, p. 311; Kavanagh, 2010b, 849-50). Después de todo, para el público general en el Reino Unido, que carece de un conocimiento detallado de los mecanismos de la HRA, una interpretación de la Sección 3 se asemeja a un visto bueno en términos de derechos humanos. Es lógico, puesto que el efecto práctico de un caso solucionado a través de la Sección 3 es que la legislación no vulnera derechos a partir de ese momento (dado que la potencial vulneración fue eliminada o "subsanada" por vía interpretativa) (Kavanagh, 2010b, p. 850). Por otro lado, es difícil presentar una declaración de incompatibilidad como otra cosa que no sea un simple fallo del Gobierno a la hora de proteger los derechos humanos (íbid., p. 849). Por tanto, aunque se piensa que el atractivo de los sistemas de revisión débil es que dan al legislador la "última palabra" en materia de derechos, la realidad es que el legislador puede no querer ejercer dicha palabra, debido a que no desea cargar con las críticas de que no respeta los derechos humanos. La experiencia del Reino Unido muestra que los gobiernos pueden preferir dejar a los tribunales las decisiones controvertidas en materia de derechos antes que iniciar un diálogo político abierto sobre dichas cuestiones.

\footnotetext{
${ }^{55}$ Kavanagh (2009), p. 132; Dixon (2009), pp. 345-346. Sobre la idea de que la confianza en la Sección 3 suele ser una consecuencia de la relativa debilidad de la Sección 4, véase más en Wintemute (2006), p. 215.

${ }^{56}$ R. (Hammond) v. Secretary of State for the Home Department, [2005] U.K.H.L. 69, paras. 17, 29 (U.K.); R. (Clift) v. Secretary of State for the Home Department, [2007] 1 A.C. 484 (H.L.), para. 40 (U.K.); Secretary of State for the Home Department v. M.B., [2008] 1 A.C. 440 (H.L.) (U.K.); Secretary of State for the Home Department v. AF (No. 3), [2009] 3 W.L.R. 74 (H.L.) (U.K.).
} 


\subsection{El efecto de la declaración de incompatibilidad}

Pasemos ahora a examinar la naturaleza e impacto de la declaración de incompatibilidad. Como hemos visto, la característica principal de esta declaración es que no vincula a las partes ni ofrece una solución a los litigantes. Ciertamente, este es el punto débil del mecanismo declarativo y la razón por la que la mayoría de los litigantes prefieren que se realice una interpretación por vía de la Sección 3. ¿Podemos, entonces, calificar a la declaración de incompatibilidad como débil? Esta es una pregunta esencial, dado que buena parte de la distinción entre las formas débil y fuerte de revisión judicial depende del hecho de que en los sistemas de revisión fuerte los tribunales tienen la facultad de anular disposiciones legislativas mediante un fallo que es final y coercitivo, mientras que en la revisión débil los tribunales cuentan solo con las llamadas "soluciones débiles", como la declaración de incompatibilidad, que dejan la última palabra al parlamento.

Pese a que la declaración de incompatibilidad no es jurídicamente vinculante para el Gobierno o el Legislativo, hay razones para sostener que no es tan "débil" como pudiera pensarse a primera vista. En primer lugar, la estructura de la HRA tiene una importante dimensión de derecho internacional, que no debe ser ignorada (véase más en Kavanagh, 2009, p. 284; Sales \& Ekins (2011), pp. 228 y ss.). Si un tribunal británico emite una declaración de incompatibilidad y el gobierno y/o el parlamento rehúsan corregir la situación, los agraviados pueden llevar el recurso al Tribunal de Estrasburgo. Allí, el interesado sostendrá que ha sufrido una vulneración en los derechos que tiene reconocidos por el Convenio (como han confirmado los tribunales superiores de su país) y que el Gobierno del Reino Unido, sin embargo, no ha corregido dicha vulneración. En esta situación, es muy probable que el Tribunal de Estrasburgo confirme la vulneración de derechos (para indagar en las razones, véase Kavanagh, 2009, pp. 284, 286-7), tras lo cual, el Gobierno del Reino Unido estará en la obligación de cambiar la legislación de acuerdo con lo establecido en la sentencia, según el derecho internacional (Kavanagh, 2009, p. 284; Lester, 1998, pp. 671, 668; Elliott, 2002, p. 348; Fenwick, 2007, pp. 199-204).

Por tanto, el Gobierno sabe que contravenir una declaración de incompatibilidad solamente sirve para posponer el problema, ya que es prácticamente inevitable que pierda el caso en Estrasburgo, con el coste en imagen que conlleva (tanto a nivel nacional como internacional). El riesgo de sufrir una dura humillación política en caso de perder en Estrasburgo constituye un fuerte incentivo para cumplir con la declaración -más cuando fue en parte para evitar dicho sonrojo que el Parlamento británico adoptó la HRA en primera instancia (Kavanagh, 2009, p. 3; Irvine, 2003, pp. 245ss; Bateup, 2009, p. 583, n. 201; Perry, 2003, p. 671). Así las cosas, el Gobierno británico tiene potencialmente poco que ganar y mucho que perder si contradice una declaración. Aunque la Declaración de Incompatibilidad se presenta a menudo como un mecanismo de carácter puramente político, tiene significativas repercusiones legales. A pesar de no ser jurídicamente vinculante en sí misma, indica que los tribunales pueden alertar al Parlamento del incumplimiento de una obligación de derecho internacional ${ }^{57}$.

En segundo lugar, hay numerosos medios de presión política para lograr que el Gobierno británico cumpla con una declaración de incompatibilidad. No se trata solo de la publicidad adversa que conlleva un fallo judicial que declara que hay una

\footnotetext{
${ }^{57}$ R. (Animal Defenders International) v. Culture Secretary, [2008] U.K.H.L. 15, p. 53 (Baroness Hale) (U.K.); R. (Countryside Alliance) v. Attorney General, [2007] U.K.H.L. 52, para. 113 (Baroness Hale) (U.K.); Sathanapally, (2012); R. (Morris) v. Westminster City Council, [2005] E.W.C.A. Civ. 1184 (C.A.), para. 56 (Sedley LJ) (U.K.).
} 
vulneración de derechos, sino que este tipo de fallos son aprovechados con frecuencia por los diputados de la oposición para movilizar a la misma dentro del Parlamento frente a las políticas del Gobierno (Sathanapally, 2012). Asimismo, las declaraciones son normalmente elevadas a la Comisión Mixta para los Derechos Humanos del Parlamento, con el fin de realzar la importancia de la violación de los derechos humanos y reforzar así la presión política al Gobierno, dentro y fuera del Parlamento, para que proceda a corregir la violación (véase más en Kavanagh, 2015b). En definitiva, las repercusiones políticas de contravenir un pronunciamiento judicial sobre vulneración de derechos, junto a las repercusiones legales de un altamente probable fallo en contrario en Estrasburgo, unidas a la relación de cortesía mutua entre el Parlamento y los tribunales y al respeto generalizado a las decisiones de estos últimos, provoca que una declaración de incompatibilidad tenga mucha más fuerza en la práctica de la que se colegiría de su estatus jurídico no vinculante (Kavanagh, 2009, 278).

En tercer lugar, cuando se introdujo el proyecto de ley de derechos humanos en el Parlamento, muchos diputados señalaron durante el debate parlamentario que había una expectativa generalizada de que el Gobierno respetaría las declaraciones de incompatibilidad. Así, el entonces Lord Canciller declaró que "esperamos que tanto el Gobierno como el Parlamento sean requeridos, seguramente en todos los casos, a cambiar la legislación de acuerdo con las declaraciones de incompatibilidad" ${ }^{28}$. Esta expectativa, calificada por una parte de la doctrina como una "expectativa constitucional" (Jowell \& Cooper, 2003, p. 3), ha sido corroborada en la práctica.

Desde la promulgación de la HRA se han dado 21 declaraciones de incompatibilidad y en casi todos los casos el Gobierno/Parlamento han actuado para corregir de alguna manera la violación de derechos ${ }^{59}$. Es cierto que el cumplimiento en algunos casos podría calificarse como mínimo y perezoso, y que en los últimos tiempos ha venido acompañado de un discurso político que exacerba los problemas de las decisiones judiciales (particularmente de las sentencias del Tribunal de Estrasburgo) sobre los derechos del Convenio ${ }^{60}$. Además, las declaraciones se han implementado con un considerable retraso ${ }^{61}$. Sin embargo, "hasta la fecha no ha habido un caso donde el Gobierno o el Parlamento haya optado deliberadamente por no corregir una legislación incompatible" (King, 2015). A pesar de los retrasos y de los discursos negativos, hay una ratio casi perfecta de cumplimiento con las declaraciones de incompatibilidad desde que la HRA fue promulgada (Young, 2011, 779).

La única posible excepción se encuentra en una declaración de incompatibilidad relacionada con la exclusión del derecho de sufragio activo a las personas que se encuentran en prisión, donde el Gobierno se ha demorado casi diez años para abordar una modificación legislativa, a pesar de las numerosas sentencias del Tribunal de Estrasburgo indicando que una prohibición total del derecho al voto a quienes cumplen condena en prisión vulnera el Convenio (véase Bates, 2014). El caso sobre el derecho de sufragio activo tiene rasgos peculiares. El primero es que todos los principales partidos políticos del Reino Unido están de acuerdo en denegar a los reclusos dicho derecho. El segundo es que se considera

\footnotetext{
${ }^{58}$ Citado en Burden v. UK, (2006) 21 B.H.R.C. 640, para. 22 (U.K.). Ver también K.D. Ewing (1999), p. 92; Fenwick (2007), p. 190; Hiebert (2006), pp. 15-6.

${ }^{59}$ U.K. Ministry of Justice, Report to the Joint Committee on human rights on the Government's Response to human rights judgments 44 (Oct. 2013); Chandrachud (2014).

${ }^{60}$ Véase la reacción política tras la sentencia del Tribunal de Estrasburgo en el caso Hirst v. U.K., [2005] E.C.H.R. 681. Ver también Murray (2013a).

${ }^{1}$ Sobre este problema, véase King (2015); Van Zyl Smit (2011), pp. 74-76; Amos (2009), p. 893.
} 
que la oposición a otorgar a los reclusos el derecho a voto no tiene coste electoral, debido a que las élites políticas piensan que dicha opción concuerda con la opinión popular. Raramente se cumplen estas dos condiciones. Así las cosas, si estas fueran las condiciones bajo las que una declaración de incompatibilidad puede ser contravenida o ignorada, son condiciones difíciles de alcanzar. Serán cumplidas solo en circunstancias excepcionales. Ciertamente, el discurso político en esta materia puede llegar a ser a veces desafiante, con políticos sugiriendo que ignorarán o desobedecerán la sentencia de Estrasburgo o, incluso, que retirarán al Reino Unido del Convenio. Aun así, la Comisión parlamentaria en la materia ha recomendado al Gobierno que implemente el fallo de alguna manera ${ }^{62}$. Está por ver cómo reaccionará el Gobierno. Por el momento continúa sin hacer nada.

El alto grado de cumplimiento de las declaraciones de incompatibilidad ha llevado a parte de la doctrina a sugerir que puede estar desarrollándose un tipo de convención constitucional por la que el Parlamento se cree en la obligación constitucional de cumplir con las declaraciones de incompatibilidad (Kavanagh, 2009, p. 289; King, 2015; Vermeule, 2012; Elliott, 2002, p. 340; Klug, 2017). Para que dicha convención constitucional existiera se requeriría de una práctica política frecuente que fuera considerada como políticamente (aunque no legalmente) vinculante por parte de los actores institucionales más relevantes (ver, por ejemplo, Jennings, 1959; Jaconelli, 1999). Probablemente sea demasiado pronto para llegar a una conclusión sobre si el cumplimiento de las declaraciones de incompatibilidad ha alcanzado el estatus de convención constitucional, aunque cada vez hay más pruebas en ese sentido. Desde luego, existe "la práctica casi uniforme de enmendar la legislación como respuesta (a las declaraciones)" (King, 2015). En esta línea, muchos periodistas y líderes políticos del Reino Unido califican las resoluciones basadas en las declaraciones de incompatibilidad de vinculantes o señalan que tienen el efecto de "revocar" o "derogar" la legislación ordinaria (Sathanapally, 2012, pp. 154, 192). Incluso cuando los parlamentarios expresan su desacuerdo con una declaración de incompatibilidad, la presentan como una "decisión normativa, no una mera opinión o consejo" (id., p. 192), sugiriendo que están obligados a darle cumplimiento (id., p. 168).

Jan Van Zyl Smit aporta una explicación para este hecho. Este autor sostiene que podría ser una forma rudimentaria de escurrir el bulto, que permite a los Ministros no tener que cargar con la responsabilidad de decisiones impopulares, dado que la crítica se dirige hacia los tribunales (Van Zyl Smit, 2011; Davis, 2010, pp. 92-93; Murray 2013b; Hirschl, 2013, p. 1089; véase también Graber, 1993). Habría otra explicación menos cínica de esta cuestión. Puede ser que, simplemente, en países donde los tribunales gozan de una alta consideración y donde hay un convencimiento compartido sobre la importancia de proteger los derechos y el imperio de la ley dentro de una cultura constitucional, los fallos de los tribunales superiores (sean o no declarativos) son tratados en la práctica como vinculantes o, como mínimo, como decisiones argumentadas y, en la mayoría de casos, dignas de ser respetadas (Bateup, 2009, 566, n.138) ${ }^{63}$. Si esto es cierto, entonces es poco probable que los novedosos mecanismos eminentemente asociados a los modelos de "revisión débil" (concretamente, la declaración de incompatibilidad en el Reino Unido y la "notwithstanding clause" canadiense) satisfagan su promesa de dar al legislativo la "última palabra" en las cuestiones relacionadas con derechos -al

\footnotetext{
62 Joint Committee on the Draft Voting Eligibility (Prisoners) Bill, Report, Session 2013-14 (16 de Diciembre de 2014). Disponible en la siguiente dirección electrónica: http:// www.publications.parliament.uk/pa/jt201314/jtselect/jtdraftvoting/103/103.pdf. (fecha de consulta: 27 de Julio de 2017).

${ }^{63}$ Para reflexiones acerca de si la forma débil de revisión judicial puede ser trasladada a otras culturas constitucionales, véase Hirschl (2013), pp. 1086, 1088 y ss.
} 
menos en el sentido de permitir a los representantes electos el discrepar de las decisiones de los tribunales superiores en materia de derechos de forma frecuente, libre y abierta. Esta explicación tendería a concordar, además, con las opiniones de quienes sostienen que una convención constitucional sobre el cumplimiento está en proceso de desarrollo.

Asimismo, puede resultar dudosa la plausibilidad de presentar a los sistemas como el británico incorporando un "modelo dialógico de protección de derechos" (Hiebert, 2006; Bateup, 2009; Young, 2009, cap. 5; Hickman, 2005), al menos si la metáfora del diálogo es tomada como una conversación entre iguales combinada con el recurso de que el legislador tome la decisión final (Crawford, 2014, p. 46) ${ }^{64}$. La realidad empírica no se corresponde con la imagen del diálogo. Por lo general, el Parlamento británico acepta los fallos judiciales que declaran que los derechos del Convenio se han vulnerado en un caso particular, y concibe que su papel es diseñar la solución apropiada que corrija la violación de una forma no excluida por la decisión judicial (King, 2015; Sathanapally, 2012, p. 5; Chandrachud, 2014, p. 625). Esto se parece menos a una conversación abierta y más a un sistema complejo de división del trabajo en el que cada rama del estado desarrolla una función diferente (aunque complementaria) en la protección de derechos.

La efectividad de las distintas formas de presión sobre el Parlamento para que termine enmendando la legislación en cumplimiento de las declaraciones de incompatibilidad ha llevado a parte de la doctrina a sugerir que, aunque los tribunales del Reino Unido no tienen formalmente la facultad de derogar legislación, "en la práctica lo hacen de forma indirecta, dado que el Gobierno procederá a cambiar la ley con casi total seguridad" (Ewing, 1999, p. 92; Lester, 1998, p. 668; Fenwick, 2007, pp. 190, 199 y ss.). Aunque en teoría tiene un carácter exhortatorio, la práctica de las declaraciones de incompatibilidad se parece "a una facultad judicial de facto para proceder a enmendar la legislación que vulnera derechos fundamentales", similar a un poder para derogar (Elliott, 2002, p. 349; Lester, 1998, p. 672; Ewing, 1999, p. 92; Sales \& Ekins, 2011, p. 230). Lord Horrmann ha sugerido -fuera de su función judicial- que la diferencia entre un poder de derogación y una declaración de incompatibilidad es meramente "técnica", ya que "cuando el tribunal realiza una declaración de incompatibilidad, la presión política al gobierno y al Parlamento para que armonicen la norma es difícil de resistir" (Hoffmann, 1999, 160). Ciertamente, si las declaraciones de incompatibilidad se han acatado en casi todos los casos, es que tienen un efecto similar a una derogación, en el sentido de asegurar que en última instancia se cambia la legislación en línea con el pronunciamiento judicial sobre las exigencias en materia de derechos humanos (Kavanagh, 2009).

La principal diferencia entre ambos poderes radica en el hecho de que una declaración de incompatibilidad no tiene efecto inmediato en la legislación y no proporciona beneficios inmediatos para el litigante. Como hemos visto, la falta de efecto retroactivo que acompaña a una declaración de incompatibilidad no carece de importancia. Incentiva a los tribunales a adoptar interpretaciones compatibles con los derechos -incluso cuando retuerce el lenguaje de la normativa (Dixon, 2009, p. 346; Choudhry y Roach, 2003). También puede desincentivar a los potenciales litigantes a la hora de alegar problemas relacionados con los derechos humanos en aquellos casos en los que la vulneración de derechos está íntimamente relacionada con un elemento fundamental del marco legislativo, ya que esto excluiría la posibilidad de una interpretación por vía de la Sección 3. Sin embargo, la

\footnotetext{
${ }^{64}$ Para un análisis crítico acerca de la utilidad de la metáfora del diálogo, véase Kavanagh, 2009, pp. 128-32, 408-411; Sathanapally, 2012, pp. 38 y ss.; MacDonald, 2004, p. 5.
} 
consecuencia habitual, más que dejar una laguna en la que los derechos no son protegidos por los tribunales, es la de reforzar la protección de derechos a través de la interpretación creativa. Esto cambia la forma en que los derechos son protegidos, pero no hace que la protección sea necesariamente más débil. De hecho, cabe argumentar que -en contra de las clasificaciones hipotéticas de Tushnet- este tipo de revisión otorga a los jueces una mayor participación en la protección de derechos de lo que ocurre en los sistemas de revisión fuerte.

\section{El papel de los tribunales en la aplicación del derecho público}

\subsection{El dilema de la autocontención judicial}

Uno de los retos más importantes al que se enfrentan los tribunales en los asuntos sobre derecho público es el de determinar los límites propios de su función constitucional. Cuando una parte en el litigio alega que sus derechos fundamentales están en juego, ¿hay alguna circunstancia que aconseje al tribunal abstenerse de la protección de los derechos o, al menos, abstenerse de hacerlo en un grado óptimo? Los jueces poseen formación y conocimientos jurídicos, pero a veces llevan a cabo su función decisoria en condiciones de incertidumbre. Pueden no tener una visión de conjunto sobre el contexto político, social o económico que envuelve una decisión o, en caso de que lo tuvieran, pueden no encontrarse en la mejor posición para evaluar sus implicaciones en un contexto más amplio. Cuando el legislativo o el ejecutivo reclama tener un mayor conocimiento o pericia respecto de un caso particular, ¿se justifica que los tribunales actúen con cierta modestia, cautela y deferencia? Incluso más allá de las consideraciones acerca de la pericia de cada uno, ¿la relativa falta de legitimidad democrática de los jueces debería obligarles a contenerse cuando examinan si las decisiones de los poderes de origen electo son conformes a los derechos fundamentales?

Estas son algunas de las cuestiones más importantes y debatidas en la teoría y el derecho constitucionales. Claramente, el grado de contención ejercido por los tribunales tiene una repercusión directa en la mayor o menor constricción efectiva del legislativo/ejecutivo por los derechos, y en el mayor o menor respaldo judicial a los reclamos de derechos individuales. Incluso dejando de lado la importancia práctica para el resultado de los casos individuales, la cuestión sobre la contención judicial nos obliga a reflexionar sobre cuestiones teóricas de mayor alcance relacionadas con la separación constitucional de poderes entre las tres ramas del estado. Nos invita a considerar qué deben hacer los tribunales y, sobre todo, qué no deben hacer. Asimismo, nos exige pensar detenidamente acerca de la naturaleza del razonamiento judicial y sobre si es apropiado que los jueces tengan en cuenta el efecto de sus decisiones en la reputación de la judicatura. Por último, la pregunta sobre la conveniencia o idoneidad de la contención judicial pone en cuestión nuestros compromisos teóricos más firmes sobre la naturaleza y función de los derechos, particularmente en lo que concierne a si los derechos son o deberían ser inmunes a consideraciones consecuencialistas.

La contención judicial plantea a los tribunales un dilema. ¿Cómo van a ejercer los jueces un grado apropiado de contención sin ceder a los poderes electos las cuestiones que afectan a la legalidad de las decisiones impugnadas? $\mathrm{O}$, en otras palabras, ¿cómo pueden los tribunales defender los derechos humanos sin sobrepasar los límites de su papel constitucional? No hay una solución fácil para este dilema, pero para analizarlo, necesitamos tener una percepción clara de las razones y argumentos que justifican la autocontención judicial. De forma concisa, mi posición es que los límites institucionales de los tribunales a veces justifican la 
autocontención judicial. Hay veces en que los jueces deben estar dispuestos a pronunciarse firmemente frente al ejecutivo o al legislativo, pero hay otras ocasiones donde deberían ejercer sus competencias con prudencia y cautela.

Dividiré mi razonamiento en cinco apartados. En primer lugar, intentaré definir qué entiendo por autocontención judicial (3.2). En segundo lugar, examinaré las razones que justifican dicha autocontención (3.3). En tercer lugar, abordaré el que considero que es el principal argumento frente a la autocontención, esto es, que puede llevar a los jueces a abstenerse de la protección de derechos o, al menos, de protegerlos en un grado óptimo (3.4). En cuarto lugar, examinaré la vía por la que el deseo de salvaguardar la reputación de los tribunales puede dar lugar a la contención (3.5). En último lugar, abordaré la posibilidad de que los jueces tengan razones para contenerse, no sólo en el resultado de sus decisiones, sino también en la forma en que expresan, presentan y justifican las mismas (3.6).

\subsection{Un intento de definición}

La autocontención judicial es una característica generalizada en el proceso judicial de toma de decisiones. Se puede decir que en casi todos los casos los jueces toman en consideración si deben contenerse más o menos. De una forma u otra, un juez siempre se enfrenta a la decisión de innovar o contenerse, entendiendo por "innovación" el desarrollo judicial de la norma y la creación judicial de derecho y por "contención" la actitud de limitarse al derecho positivo, absteniéndose de explorar una solución más creativa. En este sentido, la autocontención judicial se refiere tanto a la disposición de los tribunales a cambiar o desarrollar la ley como a su sentido de cuándo y por qué es adecuado actuar asi $i^{65}$.

En la literatura académica, la autocontención judicial abarca una amplia variedad de doctrinas, entre las que se incluyen la deferencia al proceso de decisión legislativo y/o administrativo, el respecto por el precedente (y la renuencia a la anulación), la aproximación literal o constructivista a la interpretación normativa, las doctrinas sobre la legitimación activa y sobre las cuestiones sin relevancia jurídica, los principios prudenciales como el "floodgates argument" e, incluso, la supuesta exigencia de que los jueces deben evitar hacer elecciones morales o sobre directrices políticas ${ }^{66}$. El punto que todo este variado conjunto de doctrinas tiene en común es la convicción de que los tribunales deberían mostrar cautela y contención con respecto a las opciones que se les presentan en su función decisoria.

En la resolución de disputas de derecho público, la cuestión de la contención judicial tiene una dinámica propia. Este trabajo se centra en la revisión constitucional, concretamente en la potestad que tienen los tribunales para revisar y analizar las decisiones del legislativo (por ejemplo, la legislación ordinaria) en lo referente a su conformidad con los derechos humanos. En la revisión constitucional, la contención judicial determina el grado en que, o la intensidad con la que, los tribunales están dispuestos a examinar la decisión del legislativo y la justificación aportada en respaldo de dicha decisión. La contención indica una menor intensidad o exigencia probatoria a la hora de examinar la legislación ${ }^{67}$. Puede llevar a la decisión de no resolver sobre un asunto, como ocurre cuando un tribunal aplica la doctrina de la no-justiciabilidad. Como alternativa, los tribunales pueden decidir

\footnotetext{
${ }^{65}$ Así, el "activismo judicial" en materias sujetas a revisión constitucional suele definirse como la disposición de los tribunales a desafiar la legislación alegando que viola derechos; véase a modo de ejemplo, Waldron (2005), p. 441.

${ }^{66}$ Para una visión de conjunto, véase Daley (2000), p. 279; véase también Posner (1996), pp. 314-34.

${ }^{67}$ Por ello, Guy Davidov caracteriza a la deferencia judicial en la jurisprudencia constitucional de Canadá de revisión constitucional suave o laxa; ver Davidov (2002).
} 
pronunciarse sobre la cuestión, pero de un modo menos intenso o fiscalizador del que hubieran utilizado en otras circunstancias (véase más en King, 2008; Kirk, 2001).

Antes de continuar con la justificación de la contención judicial en la resolución de materias de derecho público, debemos realizar algunas aclaraciones. En primer lugar, la contención judicial es una cuestión de grado. Un juez puede contenerse más o menos y puede evidenciar dicha contención de formas diversas. La contención judicial nada tiene que ver con el simple reclamo de que los jueces no deban interferir en las decisiones del legislativo o de que la legislación nunca pueda ser revisada de una manera exhaustiva y fiscalizadora, sino con el principio de que los jueces deberían tener un cierto grado de contención en ciertas circunstancias (ver también Daley, 2000, pp. 279, 292). Más aún, los modos en que los tribunales pueden ejercer esa contención son múltiples y variados. En algunos casos, pueden abstenerse de derogar una ley y criticarla, sin embargo, de manera firme y explícita. En otros, pueden derogar una disposición normativa, pero aplacar el golpe expresándose de una manera deferencial y moderada. Los jueces pueden mostrarse contenidos en la forma y ser, en cambio, firmes y "activistas" en el contenido de sus decisiones, o viceversa ${ }^{68}$.

En segundo lugar, la contención judicial es una cuestión de auto-contención. Son los tribunales quienes delinean los límites de su papel en las decisiones constitucionales y quienes determinan el grado apropiado de contención en dicho campo. Así, la contención judicial no se asocia a las facultades legales que tienen atribuidas los tribunales. Más bien, está relacionado con la conveniencia de que no ejerzan dichas facultades o que se moderen a la hora de utilizarlas.

En tercer lugar, cuando dictaminan que una normativa vulnera derechos humanos, los tribunales limitan el poder del legislativo para promulgar la normativa que desee (Macklem, 2006, pp. 109 y 122-4). De aquí se colige que cuanto más dispuestos se muestren los primeros a declarar que una normativa viola los derechos humanos, mayor será el límite que impondrán a los poderes electos. Por tanto, la contención judicial a la hora de resolver sobre materias de derecho público tiene una relación directa con el legislativo y el ejecutivo. Por este motivo, algunos autores consideran la contención judicial como una exigencia derivada de la necesidad de que los jueces no contradigan o interfieran con las decisiones de los otros poderes del estado (Posner, 1996, p. 314). En este trabajo, utilizo una noción de "interferencia con" el legislativo deliberadamente vaga. No se limita a la "derogación" de legislación, sino que se incluye también otros mecanismos a través de los que se ejerce la facultad judicial de revisar si una normativa cumple con los derechos humanos, como la interpretación creativa. Esto provoca que la defensa de la contención judicial tenga un grado de generalidad que le permita ser aplicable tanto a sistemas en los que existe facultad derogatoria como a aquellos en los que no, como el Reino Unido ${ }^{69}$.

\footnotetext{
${ }^{68}$ Un ejemplo de este fenómeno puede encontrarse en $R$. (Abbasi) v. Foreign Secretary and Home Secretary [2003] U.KH.R.R. 76, en el que el Tribunal de Apelación de Inglaterra rechazó que la negativa del Secretario de Exteriores británico a pedir la liberación de personas detenidas en Guantánamo, que no contaban con la nacionalidad británica, fuera ilegal, lo que no evitó que criticara la situación en Guantánamo en términos explícitos en 64-6; véase más en Endicott (2003), pp. 101-4.

${ }^{69}$ Para un análisis más detallado de los poderes de los tribunales según la HRA británica, véase Kavanagh (2009), pp. 281-93.
} 
Por último, que un tribunal se contenga no debería equivaler a que no haga nada o se muestre pasivo ${ }^{70}$. Como sabemos por nuestra vida cotidiana, ejercer contención puede requerir de una fuerte voluntad y determinación. Puede tener un carácter tan activo como una intervención. Más aún, la necesidad de justificar moralmente la contención no es menor que la de justificar una posición más intervencionista. Tampoco la contención judicial debería asemejarse a conservadurismo político. Los jueces pueden tener un pensamiento de izquierdas 0 progresista respecto a determinadas cuestiones (tales como la redistribución de la riqueza o la necesidad de intervención estatal), a la vez que respaldan la idea de contención judicial.

\subsection{Razones a favor de la contención judicial}

Tras haber definido a grosso modo el significado de contención judicial, debemos pasar ahora a la tarea de justificarla. El principal argumento de este trabajo es que la contención judicial estaría justificada por las limitaciones institucionales de los tribunales, así como por una determinada concepción de las relaciones constitucionales adecuadas entre el parlamento y el poder judicial. Permítaseme ahondar en este punto acerca de cómo influyen las limitaciones institucionales de los tribunales en el razonamiento judicial.

Al decidir sobre asuntos jurídicos, el razonamiento judicial está determinado por dos tipos de consideraciones. La primera es un análisis del contenido jurídico sustantivo de la cuestión que se dirime en sede judicial. En las resoluciones sobre materias de derecho público, tales cuestiones incluyen si la legislación viola o respeta derechos, o si una decisión tomada por un Secretario de Estado es equitativa, justa o razonable. Evaluar este tipo de cuestiones jurídicas substantivas es la primera tarea de los tribunales. Esto les exige establecer qué es lo que prescribe la ley para un determinado caso. Podemos calificar este tipo de consideraciones como "razones substantivas". Ahora bien, este no es el único tipo de planteamientos que influye en el razonamiento judicial. También son relevantes las que podríamos denominar como "razones institucionales". Este tipo de razones exigen al juez plantearse el alcance y los límites de su papel institucional respecto al parlamento, así como la adecuación de su intervención en un caso particular desde un punto de vista constitucional (Kavanagh, 2009, pp. 176ff). Esto implica que los tribunales deben preguntarse no sólo cuestiones de primer orden del tipo "¿Qué exigen los derechos en este caso?", sino también cuestiones de segundo orden relacionadas con la separación de poderes constitucional, tales como "¿es adecuado que el tribunal interfiera con la disposición legislativa, teniendo en cuenta que fue promulgada por un poder democráticamente elegido tras un periodo de deliberación y mediante una amplia consulta popular?" La primera cuestión versa sobre el contenido de los derechos. La segunda es una pregunta sobre el papel de los tribunales en una democracia constitucional. Este segundo aspecto es el que da origen a la exigencia de contención judicial ${ }^{71}$.

Se pueden identificar, al menos, cuatro razones institucionales a favor de la contención judicial. Éstas estarían relacionadas con (1) la pericia judicial, (2) el carácter gradual de la creación judicial de derecho, (3) la legitimidad institucional y

\footnotetext{
${ }^{70}$ Por esta razón, me abstendré de describir la contención judicial como una "virtud pasiva", pese a que algunos de mis argumentos tienen afinidad con el persuasivo análisis sobre la contención judicial realizado por Alexander Bickel en Bickel (1962).

${ }^{71}$ Nótese que, aunque es posible distinguir conceptualmente entre los dos tipos de razones, estas pueden ser difícil de separar en la práctica. Un argumento a favor de que las decisiones constitucionales deberían depender, en parte, de razonamientos de segundo orden relacionados con la capacidad institucional, puede verse en Sunstein (2006).
} 
(4) la reputación de la judicatura. Examinemos estas razones una a una. La restricción relacionada con el "pericia limitada" tiene su origen en las limitaciones epistémicas de los tribunales a la hora de evaluar ciertos asuntos. En situaciones en las que el juez no sabe (o no sabe con seguridad) cómo se debe resolver un problema particular 0 , mejor aún, en la que desconoce cuáles serán las consecuencias de su decisión, esa incertidumbre puede aconsejar un cierto grado de contención judicial (Kavanagh, 2009, pp. 183-90; véase también Kavanagh, 2008, pp. 194-200).

El segundo argumento a favor de la restricción viene dado por el carácter gradual de la creación judicial de derecho. Mientras que los legisladores son relativamente libres para iniciar la tramitación de un proyecto legislativo en un determinado tema, y se pueden embarcar en una reforma integral de una determinada área del derecho, los jueces están mucho más constreñidos. Por lo general, la creación judicial suele ser gradual y fragmentaria -se encarga de cubrir los vacíos del marco legal existente, para lo que trata con una disposición legislativa en cada caso en vez de reformar la ley o el área del derecho en su totalidad. Esto provoca lo que Joseph Raz ha llamado "el dilema de la reforma parcial" (Raz, 1979, p. 200) -un dilema, debido a que los tribunales se ven con asiduidad enfrentados a la elección entre dejar una disposición legal intacta (por ejemplo, no interfiriendo con la misma) o reformarla de una forma necesariamente parcial o fragmentaria. Los jueces son conscientes de que las reformas parciales pueden suponer un verdadero riesgo, ya que pueden ser contraproducentes o no lograr el objetivo deseado ${ }^{72}$. Estos problemas pueden aconsejar la contención judicial.

La tercera razón en apoyo de la contención está relacionada con la legitimidad institucional. En ocasiones, los tribunales se contienen antes de interferir con la legislación ordinaria debido a que, están preocupados porque su decisión de cambiar una ley no sea aceptada por la opinión pública o por los otros poderes del estado como consecuencia de una percepción de los tribunales como carentes de legitimidad democrática y de una rendición electoral de cuentas. Aunque esto ha generado cierta controversia dentro de la academia británica de derecho público (véase, por ejemplo, Jowell, 2003, p. 596; una respuesta a los argumentos de Jowell puede encontrarse en Kavanagh, 2009, pp. 191-193), no es difícil encontrar pronunciamientos por parte de los jueces en los que sostienen que sus resoluciones deberían respetar las decisiones del legislativo, dada su mayor legitimidad democrática ${ }^{73}$.

El cuarto argumento se basa en cuestiones de reputación. Los jueces deben dictar sus decisiones de un modo en que se preserve la buena imagen pública de la judicatura y se inspire confianza en su papel de tercero imparcial que llega a decisiones justas. Los tribunales deben asegurar que, en la medida de lo posible, sus decisiones sean respetadas -tanto por los poderes políticos (el parlamento y el ejecutivo) como por el conjunto de la opinión pública-, por lo que trataran de eludir las decisiones que causen un daño a su reputación. Más adelante examinaremos este argumento con mayor detalle.

\subsection{La interacción entre las razones sustantivas e institucionales}

Una vez que tenemos una idea general de las razones que aconsejan la

\footnotetext{
${ }^{72}$ Cass Sunstein defiende cierto grado de contención judicial en aquellos casos en que el escándalo público haría que la decisión judicial fuera inútil, contraproducente o hiciera más mal que bien, Sunstein (2007), pp. 170-2.

${ }_{3}$ Para un ejemplo de este fenómeno de la jurisprudencia relacionada con la HRA británica, de 1998, véase Kavanagh (2009), pp. 190-7.
} 
contención judicial, necesitamos algo más de claridad sobre cómo se interrelacionan las razones sustantivas e institucionales. Las "razones sustantivas" (p. ej., aquellas referidas al contenido de los derechos) deben ser las primeras en tomarse en consideración por los jueces en la revisión constitucional, ya que son las que propiamente definen la tarea judicial de examinar las decisiones legislativas y administrativas. Pero esto no significa que estas sean las únicas razones a tener en cuenta, o que siempre resulten decisivas. Los jueces deben evaluar los reclamos sobre derechos sustantivos siendo sensibles a las limitaciones institucionales del proceso judicial y a la idoneidad constitucional de su intervención en un asunto determinado ${ }^{74}$. En el esfuerzo por llegar a la mejor decisión posible, que tenga en cuenta todas las circunstancias, los tribunales deben sopesar tales limitaciones frente a las razones sustantivas relevantes del caso concreto.

Este proceso de ponderación es un rasgo distintivo del proceso de toma de decisiones en materia de derecho público que se lleva a cabo en los tribunales británicos. Un ejemplo se encuentra en el conocido fallo de Sir Thomas Bingham M. R. en $R v$. Ministry of Defense, ex parte $S m i t h{ }^{75}$ : "Cuanto más sustancial sea la interferencia con los derechos humanos, mayor será la exigencia del tribunal respecto a la justificación antes de reconocer que la decisión impugnada es razonable" ${ }^{\prime 76}$. En esta declaración se condensa la exigencia de que los tribunales ponderen los argumentos sustantivos y los institucionales, en un esfuerzo por alcanzar el mejor resultado posible para el caso concreto. La gravedad de las vulneraciones a los derechos humanos juega en contra de los argumentos a favor de la contención. Esto significa que las cuestiones institucionales acerca del grado en el que los jueces deberían deferir en el agente decisor principal dependen, en parte, de las materias en discusión en el lado sustantivo de la balanza. Es más probable que las consideraciones institucionales se impongan cuando las razones substantivas son más débiles. Sin embargo, cuando se está en presencia de una vulneración clara y sustancial de derechos, esta puede pesar más que las preocupaciones acerca del conocimiento, la incertidumbre o las consecuencias políticas. En dichas situaciones, la ponderación puede inclinarse en favor de la intervención judicial y no de la contención.

Parte de la academia se opone ferozmente a la idea de que los jueces puedan o deban tener en cuenta razones institucionales a la hora de revisar si la legislación cumple con los derechos humanos (véase más en Allan, 2006, pp. 689, 675; para una respuesta a las opiniones de Allan sobre la deferencia judicial, ver Kavanagh, 2010c). Trevor Allan considera que la contención judicial supone una "renuncia a la responsabilidad judicial" (Allan, 2006, p. 675) de proteger los derechos. La contundente crítica elaborada por Allan trae a primer plano las preocupantes y desagradables consecuencias que pueden acompañar a la contención judicial; concretamente, que si los jueces se auto-restringen a la hora de decidir en casos sobre derechos humanos, puede haber reivindicaciones de derechos que queden sin reparación. La persona concreta no obtendrá justicia -o al menos no la obtendrá en un grado satisfactorio. Un autor canadiense lo ha expresado sucintamente así: dado que la contención judicial conlleva "la relajación de las obligaciones del estado, recorta derechos constitucionales" (Davidov, 2002, p. 135). ¿Cómo puede justificarse este hecho? Más aún, los derechos se conciben

\footnotetext{
${ }^{74}$ Para un estudio sobre cómo la ponderación entre razones sustantivas e institucionales se hace evidente en la jurisprudencia bajo la HRA británica de 1998, particularmente a la hora de elegir entre realizar una interpretación según la Sección 3(1) de la HRA o la emisión de una "declaración de incompatibilidad" de la sección 4 de la HRA, véase Kavanagh, (2009), pp. 133-7.

${ }^{75}$ R. v. Ministiy of Defence, ex parte Smith [1996] Q.B. 517.

${ }^{76}$ Ibid., p. 554. Para una discusión más detallada sobre la interacción entre las razones substantivas y las institucionales, ver Kyritsis (2017), cap. 7.
} 
normalmente como inmunes a las consideraciones consecuencialistas. En esta línea, Ronald Dworkin elaboró el conocido argumento de que son "triunfos", en el sentido de que no deberían ser vulnerables a los cotidianos cambios de criterio sobre la utilidad social (Dworkin, 1984). Ciertamente, uno no necesita ser un fiel seguidor de Dworkin para tener graves reservas ante la posibilidad de que los jueces no protejan los derechos con el objetivo de salvaguardar su propia reputación o de evitar una reacción hostil por parte de la opinión pública. A decir verdad, ¿es ilegítimo este crudo intercambio entre derechos y razones prudenciales siendo el verdadero propósito de los derechos la defensa contra las políticas oportunistas? ${ }^{77}$.

Este es, sin duda, un importante desafío, construido sobre las creencias más comunes acerca de la naturaleza y la función de los derechos y sobre el papel de los tribunales en su defensa. Sin embargo, creo que el argumento está no obstante mal orientado. Permítaseme comenzar a responder a dicho desafío haciendo una observación acerca de las teorías de la contención en general. El supuesto problema en relación con la contención judicial surge, en parte, del hecho de que las teorías sobre la contención parecen tener un carácter paradójico (Raz, 1986, pp. 110-111; Raz, 1998a, pp. 47-8; Enoch, 2009, p. 45). Allan está en lo cierto al señalar que la contención de los jueces puede suponer la no corrección de una injusticia en la legislación ordinaria. Esto, a su vez, sugeriría que los jueces no deben actuar por razones de justicia, a pesar de que el argumento principal para dar a los jueces la facultad de revisión constitucional ( $\mathrm{y}$, de este modo, aislarlos de la presión directa por parte de la opinión pública) es precisamente asegurar que la legislación cumple con los requisitos de la justicia (Endicott, 2009, p. 10). No hay, sin embargo, nada paradójico en las doctrinas sobre la contención: en ocasiones tenemos buenas razones para no actuar según lo que reconocemos como buenas razones especialmente cuando operamos dentro de un marco institucional ${ }^{78}$. Aunque parezca paradójico, los jueces a veces se abstienen de enmendar injusticias contenidas en la legislación ordinaria, si entienden que al hacerlo causarían más mal que bien. Los derechos no son el único valor a tomar en consideración a la hora de decidir cuestiones de derecho público. Los derechos deben ser ponderados frente a las razones institucionales referentes a los límites del papel judicial, la adecuación de la intervención judicial en ciertos contextos, así como al grado en que una decisión judicial innovadora vaya ser aceptada por el poder político y por la opinión pública en su conjunto.

En segundo lugar, pese a que las razones institucionales pueden llevar a un tribunal a abstenerse de corregir una injusticia en la legislación, no debe olvidarse que dichas razones también hacen parte de la idea de justicia ${ }^{79}$. La división del trabajo apropiada entre los tres poderes que componen una democracia constitucional es una cuestión moral, por lo que, al decidir su grado apropiado de contención, los jueces realizan un juicio moral acerca de cómo los poderes del estado deberían ser distribuidos, ejercidos y limitados (véase más en Kavanagh, 2009, pp. 200-201; Dworkin, 1998, 1730; Waldron, 2009, p. 7). Por consiguiente, lo que exige la justicia en un caso particular es aquella decisión judicial que venga respaldada por una adecuada ponderación entre las razones sustantivas e institucionales relevantes. En ocasiones, la justicia exigirá la intervención judicial; en otras, cautela y autocontención.

\footnotetext{
${ }^{77}$ Esta posición, sin embargo, también tiene sus detractores dentro de la filosofía; ver, por ejemplo, Raz (1992).

${ }^{78}$ Para una teoría de las razones excluyentes, véase p. ej., Raz (1979); para un estudio sobre las virtudes de la contención en la vida democrática, ver Wall (2007).

${ }^{79}$ Esto da a las razones en favor de la contención un carácter irónico, ver Endicott (2009), p. 10.
} 
Probablemente, esta respuesta no sea suficiente para aquellos que se oponen a la idea de auto-contención judicial. Aunque puedan reconocer que la pregunta sobre la distribución del poder puede tener naturaleza moral o normativa, no admitirán la idea de que los argumentos pragmáticos o consecuencialistas pueden incluirse en el dominio de la "moral". La gran objeción a mi argumento, dirán, es que consiente la inaceptable idea de que los jueces elijan conveniencia por encima de justicia, al menos en algunos casos. A decir verdad, ¿es inaceptable que los jueces se abstengan de tomar la decisión moralmente correcta por el mero hecho de que pueda afectar negativamente al poder judicial o de que pueda ser impopular o políticamente controvertida? Esto último, insistirían los críticos, son consideraciones de carácter consecuencialista que no deberían jugar ningún papel en el proceso judicial de toma de decisiones.

No obstante, esta crítica aparentemente devastadora descansa en algunas distinciones y asunciones de carácter dudoso. Ciertamente, la cuestión de si los jueces deben evitar los razonamientos de tipo consecuencialista, o la cuestión filosófica más amplia sobre si el razonamiento práctico puede, de hecho, dividirse entre argumentos morales y consecuencialistas, como asume la crítica que acabamos de ver, son problemas importantes y complejos que no pueden dilucidarse dentro de los confines de este artículo (ver más en Cane, 2000; Sadurski, 2009, pp. 30-31; en una perspectiva más general, ver Raz, 1999, p. 303). Quizás sea suficiente con aportar algunos ejemplos de razonamiento judicial en los que parece aceptarse la inclusión de consideraciones consecuencialistas. Cuando un juez decide sobre un caso de negligencia médica, consideramos totalmente legítimo el tomar en cuenta (como a menudo se hace) cuál sería el impacto de su decisión en la práctica médica (Woolf, 2001). Del mismo modo, si los jueces tienen que decidir sobre si un miembro de la policía tiene un deber de protección para con los miembros del público, aceptamos que los jueces tengan en cuenta las consecuencias que dicha acción tendría tanto en la labor policial y su capacidad para acabar con la criminalidad como, más en general, en el desarrollo del derecho y el papel de los tribunales ${ }^{80}$.

Este es el típico "argumento de la avalancha" ["the floodgates argument"], típico porque es una característica común y aceptada en el proceso judicial de toma de decisiones. Si un tribunal dicta una resolución donde reconoce una reclamación sobre derechos en un nivel óptimo, pero que, por ejemplo, socava por completo la capacidad de la policía para erradicar la criminalidad, tenemos un motivo para estar preocupados. Sólo los más fervientes entusiastas de los derechos podrían celebrar dicha decisión. Igualmente, si un tribunal estuviese dispuesto, por ejemplo, a dictar una decisión donde valerosamente se reconociera el derecho al matrimonio de las parejas del mismo sexo, pero intuyese que la sociedad simplemente no está preparada para ello, o que al menos no está preparada para aceptarlo por el dictado de un tribunal, entonces tendría buenas razones para la contención. Si una resolución judicial no fuera a conseguir más que una reacción negativa hacia las parejas homosexuales, incrementando la intolerancia hacía dicho colectivo y socavando el proyecto político de implementar una reforma legal (o, más aún, movilizando a la sociedad a favor de rechazar dicha reforma en su conjunto), tal resolución sería, en el mejor de los casos, inútil y, en el peor, positivamente dañina para los intereses que en primera instancia se trata de proteger mediante la reivindicación de derechos ${ }^{81}$. Las decisiones judiciales tienen efectos en el mundo

\footnotetext{
${ }^{80}$ Ver, por ejemplo, Hill v. Chief Constable of West Yorkshire [1989] A.C. 53, par. 65 (Lord Templeman).

${ }^{81}$ Véase también Sunstein, (2007), p. 174; Cole (2009), pp. 12-6; Bamforth (2007), p. 57, quienes señalan que, incluso cuando protegen los derechos de las parejas del mismo sexo, los tribunales se
} 
en el que vivimos, y no se sirve a la justicia cuando los jueces dictan resoluciones que son ineficaces, contraproducentes o perjudiciales para los intereses amparados por los derechos.

Estos ejemplos deberían servir para mostrar otro punto importante, el de que la preocupación de los jueces por las consecuencias de sus resoluciones no es un aspecto excepcional o aberrante del proceso de toma de decisiones judiciales. Por el contrario, la consideración al posible daño social o a los objetivos de política pública son parte de la "caja de herramientas tradicional del poder judicial" (Scalia, 1989 , p. 515). En este sentido, cuando examinamos la resolución de asuntos de derecho público, solemos pensar que es difícil separar las consideraciones consecuencialistas de las que podríamos identificar como consideraciones directamente morales (véase Kavanagh, 2009, p. 200-1). La dificultad a la hora de desligar ambos tipos de consideraciones es un punto a favor de quienes niegan la tradicional división del razonamiento práctico entre razones morales y de interés propio (Raz, 1999, p. 303; ver también Sadurski, 2009, pp. 30-1). Esto concuerda con mi propia opinión, ya que sostengo que, para llegar a una decisión justa, los jueces tienen que tener en cuenta las consideraciones de tipo práctico, político y consecuencialista, además de las exigencias sustantivas asociadas a los derechos. En otras palabras, un juez no puede alcanzar una conclusión aceptable sobre lo que sería la decisión justa para un caso particular si no ha evaluado el peso relativo que debe otorgar a las razones sustantivas e institucionales -entre otras cosas porque lo que la justicia o la moral exigen en una resolución particular dependerá (en parte) de las consecuencias que esta pudiera tener. Si hay buenas razones para que los jueces no interfieran con una decisión del legislativo o del ejecutivo -una razón de suficiente peso para compensar las razones sustantivas basadas en las exigencias de los derechos-, entonces no interferir es la mejor o la más justa decisión judicial.

Los firmes defensores de la revisión constitucional, que ven los tribunales como el bastión de protección de los derechos, tienden a obviar estos argumentos. Su instrucción a los jueces pareciera ser "haz lo correcto", entendiendo por correcto el proteger únicamente el derecho fundamental sobre el que verse el caso concreto. Pero los tribunales no actúan en su propio nombre. Son órganos del estado, con determinadas responsabilidades institucionales. En mi análisis, la instrucción apropiada para los tribunales sería "haz lo correcto en la medida en que puedas hacerlo responsablemente dentro de las restricciones institucionales bajo las que operas". La indicación de "hacer lo correcto" ordena a los tribunales que sean sensibles a las razones sustantivas referidas al contenido de los derechos y que procuren la preservación del imperio de la ley obligando con firmeza a los poderes electos a rendir cuentas. Pero la exigencia de que lo hagan de manera "responsable con las restricciones institucionales que definen su papel" es la parte que garantiza la contención judicial. Este requisito abre la posibilidad lógica de diferenciar entre lo que un juez pudiera decidir a título individual y lo que sería constitucionalmente adecuado decidir en su posición de juez. Lo cual también subraya el hecho de que las razones para la contención judicial tienden a ser razones "vinculadas al agente decisor" (Raz, 1998b, p. 188), es decir, pueden exigir a los jueces no interferir con la legislación ordinaria, sin que sean aplicables a otros agentes (como el parlamento o, desde luego, los ciudadanos privados). Pero este deber judicial de ser sensibles al papel institucional que tienen encomendado, con sus limitaciones, y de tomar seriamente en consideración las consecuencias adversas que pudieran tener sus decisiones, es también una responsabilidad moral.

contienen, dando cierto margen temporal al legislativo para que implemente la reforma legal en la materia. 


\subsection{Contención e imagen pública}

En este punto, trataré las razones a favor de la contención que se refieren al afán por proteger y mejorar la imagen pública de los tribunales. Las preocupaciones relacionadas con la reputación suelen llevar a los jueces a adoptar una posición contenida, en vez de intervencionista, en la toma de decisiones. Un buen ejemplo de este fenómeno lo encontramos en la forma en que la judicatura británica asumió el rol asignado por la Human Rights Act de 1998 (HRA) en el periodo inmediatamente posterior a su promulgación. En dicho periodo, Lord Woolf señaló -fuera de su función judicial- que, dada la magnitud del cambio que propiciaba la HRA, estaba justificado "cierto grado de conservadurismo": "El objetivo debe ser convencer al parlamento y al ejecutivo de que la supervisión de los tribunales tiene un carácter constructivo" (Woolf, 2003). En la misma línea, Lord Bingham consideraba -también de modo extra-judicialque, al desarrollar la nueva función decisoria asignada por la HRA, los jueces deberían guardar el debido respeto hacia los poderes elegidos democráticamente: "Eso ciertamente ayudaría a disipar los miedos de quienes ven [en la HRA] una objetable usurpación de la autoridad democrática" (Bingham, 1998, pp. 269-270). Esta preocupación también se encuentra en el comentario de Lord Justice Keene, quien advierte de que la potencial "reacción hostil por parte de opinión pública en caso de que los tribunales se excedieran de su función constitucional" (Keene, 2007, p. 210) es una de las razones que puede llevar a los tribunales a adoptar la contención judicial. En todas las jurisdicciones es fácil encontrar ejemplos en los que se demuestra que los tribunales tienen en cuenta la reacción política a sus decisiones y que se preocupan de no ser acusados de aventurismo ${ }^{82}$. Estos factores influyen claramente en las decisiones judiciales. La pregunta es si este modo de actuar es legítimo o no.

En mi opinión, sería una irresponsabilidad que los jueces fallaran sin tener en cuenta las posibles consecuencias políticas y sociales de sus decisiones, incluyendo si la decisión puede acarrear el descrédito de toda la judicatura, o si puede desencadenar una reacción violenta en la sociedad, o si la sociedad está preparada o no para dicho cambio legal, o si puede resultar contraproducente el introducir la medida en un momento concreto, o si puede mover al gobierno o al legislativo a reducir el poder de los tribunales. Aunque los jueces tienen la obligación de hacer justicia en el caso particular, no es su única obligación. También deben asegurar que los tribunales son respetados por los otros poderes del estado y por el público en general. Del mismo modo que se preocupan por hacer justicia en el caso particular, también deben velar por mantener su capacidad para cumplir dicho rol en el largo plazo.

Esto no quiere decir que las razones relacionadas con la reputación siempre deban imponerse. Hay casos en que los tribunales deciden (adecuadamente) enfrentarse a las críticas de la opinión pública o ir más allá de lo aceptado por la sociedad para hacer justicia en el caso concreto, pese a las dudas (legítimas) sobre la factibilidad de implementar la decisión ${ }^{83}$. Puede haber casos donde la injusticia tenga un carácter tan atroz que el tribunal crea que no hay otra opción, especialmente si no hay signos de reforma por parte de los otros poderes públicos (McLachlin, 2001, p. 319). Pero incluso adoptando esta posición intervencionista y "activista", los jueces deben valorar el contexto político en el que operan. Ellos son el poder más débil y dependen de los otros poderes públicos para lograr el respeto y

\footnotetext{
${ }^{82}$ Para algunos ejemplos de este fenómeno en el contexto norteamericano y canadiense, ver Tushnet (2003), pp. 829-30.

${ }^{83}$ En el contexto de Estados Unidos, Brown v. Board of Education of Topeka 347 U.S. 483 (1954) es el ejemplo clásico. Sin embargo, la dificultad de implementación de Brown, que demoró varias décadas, muestra que las razones de tipo prudencial y moral a favor de posponer dichos cambios legislativos pueden tener una enorme fuerza; ver Marmor (2005), p. 162.
} 
la ejecución de sus decisiones. A causa de esta situación de dependencia, su poder efectivo para desarrollar el derecho y hacer justicia en los casos individuales depende, en parte, de no alienarse respecto a los poderes legislativo y ejecutivo, asegurando así que sus sentencias son respetadas por el conjunto de la sociedad. Esta es una de las razones a favor de cierto grado de contención en el proceso judicial de toma de decisiones. Implica que las razones de carácter institucional pueden prevalecer a veces frente a las de carácter sustantivo en las decisiones sobre derecho público ${ }^{84}$.

\subsection{Cortesía, confrontación y sinceridad}

Ya mencionamos arriba que, incluso en los casos en que los jueces se oponen al legislador y derogan una disposición legislativa, pueden no obstante presentar su decisión de un modo deferencial y contenido. En esta sección vamos a indagar si es legítimo que los jueces ejerzan la contención cuando presentan, expresan o justifican sus decisiones. Mucha gente se opone rotundamente a esta propuesta. Señalan que los jueces deberían ser tan transparentes y francos como sea posible respecto a todos los elementos que los han llevado a tomar su decisión. La sinceridad judicial es apreciada no sólo porque se considera que mejora la transparencia en el proceso de toma de decisiones, sino también porque es un modo de limitar el poder judicial, incrementando la probabilidad de que los jueces basen sus decisiones en razones legítimas (Shapiro, 1987, p. 737).

Mucho se podría decir acerca de estas afirmaciones. La apertura, la transparencia y la rendición de cuentas pública son obligaciones de todas las instituciones públicas, incluyendo los tribunales. Nadie quiere que las decisiones judiciales estén envueltas bajo un halo de misterio o subterfugios. Sin embargo, los jueces tienen a veces buenas razones para no ser completamente sinceros respecto a los fundamentos de una decisión. La honestidad absoluta, argumentaré, no es siempre la mejor política judicial. No sólo la contención judicial exige a los jueces que se limiten en cierto grado al tomar decisiones, también los exige que se contengan en la forma en que expresan o presentar la justificación de las mismas.

Dejemos a un lado, para defender este punto, la discusión acerca del razonamiento judicial y pensemos de manera más general en el valor de la contención en, por ejemplo, ámbitos como la amistad. En ocasiones, un amigo puede realizar una acción que nos parece moralmente incorrecta. En tal situación, podemos sentirnos inclinados a ser sinceros y directos respecto a la opinión que nos merece su actuación. No obstante, la absoluta franqueza no es siempre la reacción correcta. De hecho, a veces puede ser inútil y contraproducente. La sinceridad a veces no solo no evita que los amigos sigan actuando inmoralmente, sino que contribuye a que persistan en la misma al tiempo que les enfada, pudiendo llegar a socavar dicha amistad. Todos esperamos que nuestros amigos nos apoyen, incluso en situaciones en las que no estamos haciendo lo correcto. Por tanto, el valor que sostiene la amistad, el apoyar y respetar a los amigos, justificará a veces cierto grado de contención y tolerancia, y no la sinceridad absoluta.

\footnotetext{
${ }^{84}$ Ver también Raz (1998b), p. 187. Fue David Dyzenhaus quien me indicó que es un error que los jueces se basen en argumentos sobre su reputación o prudencia porque hay casos (él mencionó Hamdi v. Rumsfeld 542 U.S. 507 (2004) como ejemplo) en los que deciden tener una actitud deferente para no irritar al ejecutivo, hasta que descubren que su estrategia de deferencia fue contraproducente o que supuso un obstáculo para la actuación judicial futura, debido a la creación de un mal precedente. Como respuesta, simplemente indicaría que, como ocurre con el "activismo" judicial, la contención judicial también tiene el riesgo de provocar un efecto indeseado o conllevar malas consecuencias políticas o legales. Sin embargo, esto no socava el argumento general en favor de la contención judicial -solamente muestra que la contención judicial debe ser ejercida con precaución y consciencia sobre las (potencialmente negativas) consecuencias futuras.
} 
Hay ejemplos menos extremos del valor de la contención en las relaciones de amistad. Muchos amigos discrepan acerca de política, música, arte y mucho más. A veces, los desacuerdos claros y sinceros en tales materias no dañan en absoluto la relación de amistad. Sin embargo, no siempre es así. Hay situaciones en las que los amigos evitan discutir sobre política, ya que saben que podría generar acritud y discordia. En ocasiones, es aconsejable minimizar el grado de desacuerdo por miedo a ofender gratuitamente a un amigo. Hay situaciones donde la contención está justificada por razones de respeto al amigo y por un deseo de conservar la amistad.

Estos ejemplos sirven para subrayar algunas de las virtudes que la contención puede tener en el contexto judicial. En primer lugar, la contención no es una cuestión de todo o nada, que se aplicaría de forma generalizada. Más bien, se debería evaluar si la contención en aconsejable en el contexto concreto y, en caso de que lo fuera, en qué medida. En segundo lugar, está fundamentada en el valor del respeto. Como muestra de respeto hacia los otros, a veces se requiere que seamos educados y amables sobre las materias en las que no estamos de acuerdo. La absoluta franqueza, en cambio, puede conducir a la ofensa, al insulto y al resentimiento. No solamente debemos respetar a nuestros amigos, sino que tiene que existir la apariencia de que efectivamente eso es asi ${ }^{85}$.

Esto también es válido para las relaciones entre los tribunales y los poderes electivos del estado. La contención judicial es a veces una muestra de respeto por la mayor competencia, pericia y legitimidad democrática de los otros poderes (véase más en Kavanagh, 2008, p. 184). Naturalmente, respeto no significa que los tribunales deban estar de acuerdo con todo lo que hacen el legislativo y el ejecutivo. El desacuerdo y el respecto no son mutuamente excluyentes. No obstante, cuando se está en desacuerdo con el parlamento, los tribunales deben expresarlo de forma respetuosa, moderada y amable. Parte de su función como jueces es convencer al legislativo y al ejecutivo de que los tribunales son un socio constructivo a la hora de defender un gobierno equitativo en el marco de una democracia constitucional ${ }^{86}$. Esta exigencia de cortesía para con los poderes de origen electo significa que los tribunales no deberían tomar decisiones que menosprecien o ridiculicen al parlamento, o que busquen deslegitimar la legislación o a las decisiones políticas que el parlamento o el ejecutivo hayan tomado. Por consiguiente, incluso si un juez considerara que el gobierno de turno está absolutamente equivocado en el desarrollo de un programa legislativo particular y que meramente se ha doblegado a las demandas de la prensa sensacionalista en un crudo intento de ganar votos antes de las elecciones, la sinceridad acerca de esta cuestión podría socavar el respeto que los jueces deben mostrar hacía los poderes electos del estado. Tal sinceridad puede distanciar al legislativo y al ejecutivo, de quienes dependen los tribunales a la hora de ejecutar sus decisiones; puede causar resentimiento y represalias por parte del poder político, y sobre todo puede ser totalmente contraproducente. En algunos casos, este hecho avala la moderación por encima de la crítica abierta.

Se puede objetar en este punto que la analogía entre los amigos, por un lado, y el parlamento y los tribunales, por otro, es engañosa debido a que el parlamento y los tribunales no tienen una relación de amistad ni nada que se le parezca $^{87}$. Hay quien cree que la relación entre el parlamento y los tribunales es más parecida a la de un siervo y su amo. Para otros, la relación se asemejaría más

\footnotetext{
${ }^{85}$ Sobre la significación moral de la educación o la cortesía como una forma de mostrar respecto, véase Calhoun (2000), p. 255; Buss (1999), p. 801.

${ }^{86}$ Endicott (2009), p. 1; ver también Dyzenhaus, (2006), donde el autor sostiene que el imperio de la ley se entiende mejor como un "proyecto compartido" entre todas las ramas del estado.

${ }^{87}$ Este argumento me fue indicado por Panu Minkkinen.
} 
a una relación de enemistad más que de amistad. Para estos, el rol de los tribunales no es apoyar al parlamento, sino frenarle, oponerse a sus decisiones si son injustas, pedirle cuentas y obligarle a respetar los derechos aunque no quiera.

Para responder a esta objeción debo señalar lo siguiente. El principal objetivo de la analogía de la amistad era simplemente mostrar la verosimilitud que a primera vista tiene la afirmación de que la franqueza total e ilimitada no es siempre una virtud. Es un lugar común el señalar que la amistad verdadera exige de la honestidad de las partes en la relación. Pero sabemos que ese tópico no sirve para explicar las relaciones de amistad en toda su complejidad. A veces, la moderación es más apropiada. Usó la amistad como un mecanismo heurístico con el que mostrar que, aunque la creencia en la importancia de la sinceridad judicial se ha convertido en un lugar común, los hechos señalan que hay buenas razones en favor de la contención judicial.

Hay otro aspecto en la analogía de la amistad que, bajo mi punto de vista, confiere a la misma cierta verosimilitud a la hora de resaltar la dimensión interinstitucional del razonamiento judicial. Este se refiere a que mantener una amistad es una empresa común que debe durar en el tiempo. Ser amigo de alguien significa que, en alguna ocasión, uno se ha mordido la lengua en una situación concreta, a fin de no dañar la relación en el largo plazo. De igual modo, en las relaciones institucionales entre los tribunales y el legislativo, los tribunales deben tener en cuenta el largo plazo y las consecuencias de sus acciones, con el objetivo de ganarse el respeto y el apoyo del poder legislativo en dicho horizonte temporal ${ }^{88}$.

Aun así, no negamos que la analogía de la amistad no puede ser llevaba mucho más allá. No trato de sugerir los tribunales y el legislativo tengan una relación cómoda, con ambas partes compartiendo siempre la misma posición en cada asunto. Por el contrario, ambas instituciones tienen sus puntos fuertes y sus debilidades. Como parte en la empresa de asegurar un gobierno constitucional equitativo, los tribunales pueden verse exigidos a enfrentarse al órgano legislativo, oponerse a una decisión legislativa y a anularla si fuera necesario. En ocasiones el legislativo y el judicial pueden presionar en distinta dirección, por lo que el legislativo se sentirá constreñido por las decisiones judiciales. Como corresponsables en la empresa, los tribunales deben estar preparados (en el contexto adecuado) para mantenerse firmes.

\section{Conclusiones}

¿Cómo pueden asegurar los jueces que la legislación cumple con los derechos humanos sin renegar de su responsabilidad de permanecer dentro de los límites del papel constitucional que tienen asignado? No hay una respuesta fácil a este dilema. Pese a que es importante remarcar que los tribunales tienen el deber de defender los derechos en tiempos de crisis, no se debe olvidar que tienen limitaciones políticas e institucionales que pueden impedir la protección efectiva de los derechos en todos los casos. De acuerdo con la teoría de la autocontención que hemos expuesto en este trabajo, los jueces deberían evaluar las razones substantivas e institucionales, teniendo en cuenta tanto las exigencias derivadas del contenido de los derechos como las consideraciones institucionales pertinentes en el caso concreto. Esta teoría subraya las deficiencias de las aproximaciones que se limitan a examinar quién tiene la "última palabra" a la hora de comprender la compleja dinámica interinstitucional que tiene lugar en el marco de la HRA. En vez de pensar en términos absolutos sobre a qué poder del

\footnotetext{
${ }^{88}$ Para una discusión más detallada sobre la idea del derecho como una "empresa compartida" entre las diferentes instituciones del estado, ver Kyritsis (2008).
} 
estado le correspondería "la última palabra" en el diálogo constitucional, la teoría de la autocontención se basa en una aproximación más amplia y realiza un análisis más profundo acerca de la naturaleza y la forma de las diferentes contribuciones realizadas por todos los poderes con el fin de proteger los derechos. Se trata de una visión más matizada, donde los tribunales y el legislador tienen una responsabilidad compartida a la hora de proteger derechos, cada cual en un rol diferente (aunque complementario). Así, en el Reino Unido, los tribunales pueden tener la última palabra sobre si un determinado derecho ha sido vulnerado en el caso particular al que se enfrenta, pero si se dicta una declaración de incompatibilidad, el parlamento será quien tenga la última palabra para decidir el modo en que se corrige dicha vulneración.

Este análisis tiene importantes consecuencias, tanto para el esfuerzo doctrinal de establecer una tipología dentro del derecho constitucional comparado como para los debates teóricos en torno a la justificación de la revisión judicial de constitucionalidad. Respecto a las tipologías de derecho comparado, recuérdese que cuando se comenzó a afirmar que las medidas de protección de derechos aprobadas en el Reino Unido, Canadá y Nueva Zelanda representaban un nuevo modelo de "constitucionalismo commonwealth" (Gardbaum, 2001), el único componente diferenciador era que parecía dar la "última palabra" sobre si y/o cómo proteger los derechos a los poderes electos del estado. Sin embargo, tras la experiencia acumulada con estos sistemas, lo cierto es que el legislador no ha usado sus poderes formales para revocar las decisiones judiciales en ningún grado significativo.

Si una de las virtudes características de la revisión judicial "débil" es que "se supone que impone un coste político para el gobierno, al llamar la atención sobre la posibilidad de que éste hubiera violado derechos constitucionales" (Tushnet, 2003, p. 834), entonces debemos afrontar el hecho de que el poder legislativo (al menos dentro de la cultura constitucional prevaleciente en los países de la Commonwealth) está normalmente poco inclinado a asumir dicho coste. Como ha observado Tushnet, "esos costes pueden ser suficientes para convertir una decisión que podría ser nominalmente inaplicada en una decisión final de facto" (id., p. 824), reduciendo así la distinción entre los sistemas de revisión judicial "débil" y "fuerte" a la mera posibilidad teórica de ejercer una potestad que nunca es puesta en práctica.

Aunque la distinción entre formas fuertes y débiles de revisión judicial nos impele a fijarnos principalmente en los canales formales para la resolución de desacuerdos entre los tribunales y los legisladores, la práctica constitucional real de estos países parece estar ocurriendo en un plano más informal, sustentada por una serie de doctrinas y recursos que facilitan diferentes formas de interacción y colaboración inter-institucional entre los tribunales y los poderes electos (Kavanagh, 2009; Hogg \& Bushell, 1997; Dixon, 2012; Young, 2011). Como consecuencia, uno de los asuntos más importantes y vehementemente discutidos en la literatura académica del Reino Unido es hasta qué punto está justificado (si es que en todo caso lo está) que los jueces defieran en las decisiones ponderadas de las asambleas democráticas y, en su caso, en qué medida. Este tipo de autocontención judicial es simplemente una forma en la que los jueces pueden calibrar su respeto hacia la competencia institucional y legitimidad de los poderes electos del estado, facilitando así una división del trabajo entre ellos. La relevancia de las diferentes doctrinas de contención judicial nos advierte que nuestras tipologías deberían moverse más allá de los enunciados formales textuales sobre la fuerza o debilidad 
de la revisión judicial, para reconocer y asumir la fuerza real de la práctica tal y como ésta se implementa y aplica por los jueces en sede judicial ${ }^{89}$.

Por último, en relación con los debates teóricos sobre la justificación de la revisión judicial de constitucionalidad, debería reconocerse que la revisión "débil" no es, en contra de lo que muchos creyeron, la solución rápida al problema de legitimidad que acarrea la revisión judicial al estilo del Tribunal Supremo de los Estados Unidos. Sin duda se creyó que una de las grandes virtudes de la revisión judicial "débil" era que solucionaba el problema de legitimidad reduciendo los poderes de los tribunales y dando a los legisladores la "última palabra" sobre si y/o cómo la legislación debe proteger los derechos. Considerada en su literalidad, la revisión judicial débil parecía resolver (o, al menos, mitigar) la tensión entre el autogobierno democrático y la revisión constitucional basada en derechos. Pero si los legisladores no desean, o al menos no afirman su poder para decir "la última palabra" en ningún grado significativo, entonces el problema de legitimidad sigue en gran medida pendiente. Este problema puede no ser insuperable, pero debe afrontarse directamente como parte del desafío justificatorio. La solución no viene necesariamente de una carta de derechos en el que se otorga al legislador la posibilidad de saltarse las decisiones judiciales; eso depende, en un sentido crucial, de cómo los tribunales y el legislador dividen la tarea constitucional entre ellos y de qué institución tiene en la práctica la última palabra.

\section{Bibliografía}

ALLAN, T. R. S. (2006), "Human Rights and Judicial Review: A Critique of 'Due Deference'", Cambridge Law Journal, 65/3, pp. 671-95.

AMOS, M. (2009), "Problems with the Human Rights Act and How to Remedy Them: Is a Bill of Rights the Answer?", Modern Law Review, 72, pp. 883-908.

BAMFORTH, N. (2007), "Same-Sex Partnerships: Some Comparative Constitutional Lessons", European Human Rights Law Review, 1, pp. 47-65.

BATES, E. (2014), "Analysing the Prisoner Voting Saga and the British Challenge to Strasbourg", Human Rights Law Review, 14, pp. 503-40.

BATEUP, Ch. (2009), "Reassessing the Dialogic Possibilities of Weak Form Bills of Rights", Hastings International Law \& Comparative Law Rev., 32, pp. 529-600.

BICKEL, A. (1962), The Least Dangerous Branch, YUP, New Haven.

BINGHAM, T. (1998), "Incorporation of the ECHR: The Opportunity and the Challenge", Jersey Law Review, 2, pp. 257-70.

BINGHAM, T. (2010), "The Human Rights Act", European Human Rights Law Review, 6, pp. 568-75.

BUSS, S. (1999), "Appearing Respectful: The Moral Significance of Manners", Ethics, 109, pp. 795-826.

CALHOUN, Ch. (2000), "The Virtue of Civility”, Philosophy \& Public Affairs, 29, pp. 25175.

CANE, P. (2000), "Consequences in Judicial Reasoning”. En: HORDER, J. (ed.), Oxford Essays in Jurisprudence: Fourth Series, OUP, Oxford, pp. 41-60.

CAROLAN, E. (2011), "The relationship between Judicial Remedies and the Separation of Powers: Collaborative Constitutionalism and the Suspended Declaration of Invalidity", Irish Jurist, 46, pp. 18-32.

CAROLAN, E. (2016), 'Dialogue isn't working: The case for collaboration as a model of legislative-judicial relations', Legal Studies, 36, pp. 209-29.

CHANDRACHUD, Ch. (2014), "Reconfiguring the Discourse on Political Responses to

\footnotetext{
${ }^{89}$ La literatura sobre la deferencia judicial debida bajo la HRA es muy extensa. Para un resumen de las posiciones más relevantes en el debate académico, véase Allan, (2006); Kavanagh (2010c); King (2008).
} 
Declarations of Incompatibility", Public Law, pp. 624-41.

CHOUDHRY, S. (2013), "The Commonwealth Constitutional Model or Models?", International Journal of Constitutional Law, 11, pp. 1094-99.

CHOUDHRY, S. y ROACH, K. (2003), "Putting the Past Behind Us? Prospective Judicial and Legislative Constitutional Remedies", Supreme Court Law Review, 21, pp. 205-66.

COLE, D. (2009), "The Same-Sex Future”, New York Review of Books (2 de julio), pp. 12-6.

CRAWFORD, Ch. (2014), "Dialogue and Rights-Compatible Interpretations under Section 3 of the Human Rights Act 1998", King's Law Journal, 25, pp. 34-59.

DALEY, J. (2000), "Defining Judicial Restraint". En: CAMPBELL, T. y GOLDSWORTHY, J. (eds.), Judicial Power, Democracy and Legal Positivism, Ashgate, Aldershot, pp. 279-314.

DAVIDOV, G. (2002), "The Paradox of Judicial Deference", New Zealand Law Journal, 12/2, pp. 133-64.

DAVIS, F. (2010), "The Human Rights Act and Juridification: Saving Democracy from Law", Politics, 30/2, pp. 91-7.

DAVIS, F. y MEAD, D. (2014), "Declarations of Incompatibility, Dialogue and the Criminal Law", Common Law World Review, 43, pp. 62-84.

DIXON, R. (2009), "A Minimalist Charter of Rights for Australia: The U.K. or Canada as a Model?', Federal Law Review, 37, pp. 335-62.

DWORKIN, R. (1984), "Rights as Trumps". En: WALDRON, J. (ed.), Theories of Rights, OUP, Oxford, pp. 153-67.

DWORKIN, R. (1998), "Darwin's New Bulldog”, Harvard Law Review, 111, pp. 1718-38.

DYZENHAUS, D. (2006), The Constitution of Law: Legality in a Time of Emergency, CUP, Cambridge.

ELLIOTT, M. (2002), "Parliamentary Sovereignty and the New Constitutional Order: Legislative Freedom, Political Reality and Convention", Legal Studies, 22, pp. 34075.

ENDICOTT, T. (2003), "The Reason of the Law", American Journal of Jurisprudence, 48, pp. 83-106.

ENDICOTT, T. (2009), "Habeas Corpus and Guantanamo Bay: A View from Abroad", American Journal of Jurisprudence, 54, pp. 1-40.

ENOCH, D. (2009), "On Estlund's Democratic Authority", Jerusalem Philosophy Quarterly, 58, pp. 35-48.

EWING, K.D. (1999), "The Human Rights Act and Parliamentary Democracy", Modern Law Review, 62, pp. 79-99.

FENWICK, H. (2007), Civil liberties and human rights, OUP, Oxford.

FELDMAN, D. (1999), "The Human Rights Act 1998 and Constitutional Principles", Legal Studies, 19, pp. 165-206.

GARDBAUM, S. (2001), "The New Commonwealth Model of Constitutionalism", American Journal of Comparative Law, 49, pp. 707-60.

GARDBAUM, S. (2013), The New Commonwealth Model of Constitutionalism. Theory and Practice, CUP, Cambridge.

GEARTY, C. (2002), "Reconciling Parliamentary Democracy and Human Rights", Law Quarterly Review, 118, pp. 248-69.

GRABER, M. (1993), "The Nonmajoritarian Difficulty: Legislative Deference to the Judiciary", Studies in American Political Development, 7, pp. 35-73.

HICKMAN, T. (2005), "Constitutional Dialogue, Constitutional Theories and the Human Rights Act 1998", Public Law, pp. 306-35.

HICKMAN, T. (2010), Public law after the Human Rights Act, Hart Publishing, Oxford.

HIEBERT, J. L. (2006), "Parliamentary Bills of Rights: An Alternative Model?", Modern Law Review, 69/1, pp. 7-28.

HIEBERT, J. L. (2012), "Parliamentary Engagement with the Charter: Rethinking the Idea of Legislative Rights Review”, Supreme Court Law Review,58, pp. 87-107. 
HIRSCHL, R. (2013), "How Consequential is the Commonwealth Constitutional Model?", International Law Journal of Constitutional Law, 11/4, pp. 1086-93.

HOFFMANN, L. L. (1999), "Human Rights and the House of Lords", Modern Law Review, 62/2, pp. 159-66.

HUNT, M. (2007), "Reshaping Constitutionalism". En: MORISON, J., McEVOY, K. y ANTHONY, G. (eds.), Judges, Transition, and Human Rights, OUP, Oxford, pp. 467-77.

HUNT, M. (2010), "The Impact of the Human Rights Act on the Legislature: A Diminution of Democracy or a New Voice for Parliament?", European Human Rights Law Review, 6, pp. 601-8.

IRVINE, D. (2003), Human Rights, Constitutional Law and the Development of the English Legal System, Hart Publishing, Oxford.

JACONELLI, J. (1999), "Do Constitutional Conventions Bind?", Cambridge Law Journal, 64/1, pp. 149-76.

JENNINGS, I. (1959), The law and the Constitution ( $5^{\mathrm{a}}$ ed.), ULP, Londres.

JOWELL, J. (2003), “Judicial Deference: Servility, Civility or Institutional Capacity?", Public Law, pp. 592-601.

JOWELL, J. y COOPER, J. (2003), "Introduction". En: JOWELL, J. y COOPER, J. (eds.), Delivering Rights: How the Human Rights Act is Working, Hart Publishing, Oxford, pp. 1-4.

KAHANA, T. (2002), "Understanding the Notwithstanding Mechanism", University of Toronto Law Journal, 52, pp. 221-74.

KAVANAGH, A. (2004), "The Elusive Divide between Interpretation and Legislation under the Human Rights Act 1998", Oxford Journal of Legal Studies, 24/2, pp. 25985.

KAVANAGH, A. (2005), 'Unlocking the Human Rights Act: The 'Radical' Approach to Section 3(1) Revisited', European Human Rights Law Review, 3, pp. 260-76.

KAVANAGH, A. (2008), "Deference or Defiance? The Limits of the Judicial Role in Constitutional Adjudication", in HUSCROFT, G. (ed.), Expounding the Constitution. Essays in Constitutional Theory, CUP, Cambridge, pp. 184-215.

KAVANAGH, A. (2009), Constitutional review under the UK Human Rights Act, OUP, Oxford.

KAVANAGH, A. (2010a), Judicial Restraint in the Pursuit of Justice, University of Toronto Law Journal, 60, pp. 23-40.

KAVANAGH, A. (2010b), "Special Advocates, Control Orders and the Right to a Fair Trial", Modern Law Review, 73/5, pp. 836-57.

KAVANAGH, A. (2010c), "Defending Deference in Public Law and Constitutional Theory", Law Quarterly Review, 126, pp. 222-50.

KAVANAGH, A. (2015a), "What's so weak about 'weak-form review'? The case of the UK Human Rights Act 1998", International Journal of Constitutional Law, 13/4, pp. 1008-39.

KAVANAGH, A. (2015b), "The Joint Committee on Human Rights: A Hybrid Breed of Constitutional Watchdog”. En: HUNT, M., HOOPER, H. J. y YOWELL, P. (eds.), Parliament and Human Rights. Redressing the Democratic Deficit, Hart Publishing, Oxford, pp. 115-40.

KAVANAGH, A. (2015c), "A Hard Look at the Last Word", Oxford Journal of Legal Studies, 35/4, pp. 825-47.

KAVANAGH, A. (2016), "The Lure and the Limits of Dialogue", University of Toronto Law Journal, 66, pp. 83-120.

KEENE, D. (2007), "Principles of Deference under the Human Rights Act". En: FENWICK, H., PHILLIPSON, G. y MASTERMAN, R. (eds.), Judicial Reasoning under the UK Human Rights Act, CUP, Cambridge, pp. 206-12.

KING, J. (2008), "Institutional Approaches to Judicial Restraint", Oxford Journal Law Studies, 28/3, pp. 409-41.

KING, J. (2015), "Parliament's Role Following Declarations of Incompatibility under the 
Human Rights Act". En: HUNT, M., HOOPER H. J. y YOWELL, P. (eds.), Parliament and Human Rights. Redressing the Democratic Deficit, Hart, Oxford, pp. 165-92.

KIRK, J. (2001), "Rights, Review and Reasons for Restraint", Sydney Law Review, 23/1, pp. 19-52.

KLUG, F. (2003), “Judicial Deference under the Human Rights Act 1998”, European Human Rights Law Review, pp. 125-33.

KLUG, F. (2007), "A Bill of Rights-Do We Need One or Do We Already Have One?", Public Law, pp. 701-19.

KYRITSIS, D. (2008), "What Is Good about Legal Conventionalism?”, Legal Theory, 14/2, pp. 135-66.

KYRITSIS, D. (2017), Where Our Protection Lies: Separation of Powers and Constitutional Review, OUP, Oxford.

LECKEY, R. (2015), Bills of rights in the Common law, CUP, Cambridge.

LESTER, A. (1998), "The Art of the Possible-Interpreting Statutes under the Human Rights Act", European Human Rights Law Review, pp. 665-80.

LESTER, A. (2002), "The Magnetism of the Human Rights Act 1998", Victoria University Wellington Law Review, 33, pp. 477-505.

MACDONALD, L. (2004), "Rights, 'Dialogue' and Democratic Objections to Judicial Review", Federal Law Review, pp. 32, 1-28.

MCLACHLIN, B. (2001), "The Supreme Court and the Public Interest", Saskatchewan Law Review, 64, pp. 309-21.

MACKLEM, T. (2006), "Entrenching Bills of Rights", Oxford Journal Legal Studies, 26/1, pp. 107-29.

MARMOR, A. (2005), Interpretation and Legal Theory (2 ed.), Hart Publ., Oxford.

MASHAW, G. (1997), Greed, Chaos and Governance: Using Public Choice to Improve Public Law, YUP, Yale.

MURRAY, C. (2013a), "A Perfect Storm: Parliament and Prisoner Disenfranchisement", Parliamentary Affairs, 66/3, pp. 511-39.

MURRAY, C. (2013b), "The Continuation of Politics, by Other Means: Judicial Dialogue under the Human Rights Act 1998". En: MASTERMAN, R. y LEIGH, I. (eds.), The United Kingdom's Statutory Bill of Rights. Constitutional and Comparative Perspectives, OUP/British Academy, Oxford, pp. 51-80.

NICOL, D. (2004), "The Human Rights Act and the Politicians", Legal Studies, 24, pp. 451-79.

NICOL, D. (2006), "Law and Politics after the Human Rights Act", Public Law, 4, pp. 722-51.

PERRY, M. J. (2003), "Protecting Human Rights in a Democracy: What Role for the Courts?", Wake Forest Law Review, 38, pp. 635-96.

PHILLIPS, N. (2010), "The Art of the Possible: Statutory Interpretation and Human Rights", The First Lord Alexander of Weedon Lecture. Disponible en la siguiente dirección electrónica: https://www.supremecourt.uk/docs/speech 100419.pdf (fecha de consulta: 25 de Julio de 2017).

PHILLIPSON, G. (2007), "Deference, Discretion, and Democracy in the Human Rights Act Era", Current Legal Problems, 60/1, pp. 40-78.

POSNER, R. (1996), The Federal Courts, HUP, Cambridge, Mass.

RAZ, J. (1979), The Authority of Law, OUP, Oxford.

RAZ, J. (1986), The Morality of Freedom, OUP, Oxford.

RAZ, J. (1992), "Rights and Individual Well-Being", Ratio Juris, 5/2, pp. 127-42.

RAZ, J. (1998a), "Disagreement in Politics", American Journal of Jurisprudence, 43, pp. 25-52.

RAZ, J. (1998b), "On the Authority and Interpretation of Constitutions: Some Preliminaries". En: ALEXANDER, L. (ed.), Constitutionalism: Philosophical Foundations, CUP, Cambridge, pp. 152-93.

RAZ, J. (1999), Engaging Reason: On the Theory of Value and Action, OUP, Oxford. 
ROACH, K. (2004), "Dialogic Review and Its Critics", Supreme Court Law Review, 23/2, pp. 49-104.

SADURSKI, W. (2009), "Rights and Moral Reasoning: An Unstated Assumption - A Comment on Jeremy Waldron's "Judges as Moral Reasoners"', International Journal of Constitutional Law, 7, pp. 25-45.

SALES, P. \& EKINS, R. (2011) "Rights-Consistent Interpretation and the Human Rights Act 1998", Law Quarterly Review, 127, pp. 217-38.

SATHANAPALLY, A. (2012), Beyond disagreement: open remedies in human rights adjudication, OUP, Oxford.

SCALIA, A. (1989) "Judicial Deference to Administrative Interpretations of the Law", Duke Law Journal, 3, pp. 511-21.

SCHAEFFER, A. (2005), "Linking Marleasing and s.3(1) of the Human Rights Act 1998", Judicial Review, 10/1, pp. 72-7.

SCHAUER, F. (1995), "Ashwander Revisited", Supreme Court Review, pp. 71-98.

SHAPIRO, D. L. (1987), 'In Defence of Judicial Candour', Harvard Law Review, 100, pp. 731-50.

SUNSTEIN, C. (2006), "Second-Order Perfectionism”, Fordham Law Review, 75/6, pp. 2867-83.

SUNSTEIN, C. (2007), "If People would be Outraged by Their Rulings, Should Judges Care?", Stanford Law Review, 60/1, pp. 155-212.

TUSHNET, M. (2003), "New Forms of Judicial Review and the Persistence of Rightsand Democracy-Based Worries", Wake Forest Law Review, 38, pp. 813-38.

TUSHNET, M. (2006), "Weak-Form Judicial Review and "Core" Civil Liberties", Harvard Civil Rights-Civil Liberties Law Review, 41, pp. 1-22.

TUSHNET, M. (2008), Weak Courts, Strong Rights: Judicial Review and Social Welfare Rights in Comparative Constitutional Law, PUP, Princeton.

VAN ZYL SMIT, J. (2011), "Statute Law: Interpretation and Declarations", in D. Hoffman (ed.) The Impact of the UK Human Rights Act on Private Law, CUP, Cambridge, pp. 66-90.

VERMEULE, A. (2012), "The Atrophy of Constitutional Powers", Oxford Journal Legal Studies, 32/3, pp. 421-44.

WALDRON, J. (2005), "Compared to What? Judicial Activism and New Zealand's Parliament", New Zealand Law Journal, pp. 441-45.

WALDRON, J. (2009), "Judges as Moral Reasoners", International Journal of Constitutional Law, 7/1, pp. 2-24.

WALL, S. (2007), "Democracy and Restraint", Law \& Philosophy, 26, pp. 307-42.

WINTEMUTE, R. (2006), "The Human Rights Act's First Five Years: Too Strong, Too Weak or Just Right?", King's Law Journal, 17, pp. 209-27.

WOOLF, H. (2001), "Are the Courts Excessively Deferential to the Medical Profession?", Medical Law Review, 9, 1-16.

WOOLF, H. (2003), "Current Challenges in Judging" (Fifth Worldwide Common Law Judiciary Conference, Sydney, Australia). Disponible en la siguiente dirección electrónica: http://ww.judiciary.gov.uk/publications media/speeches/ pre 2004/lcjl00403.htm (fecha de consulta: 25 de Julio de 2017).

YOUNG, A. L. (2009), Parliamentary Sovereignty and the Human Rights Act, Hart Publishing, Oxford.

YOUNG, A. L. (2011), “Is Dialogue Working under the Human Rights Act 1998?", Public Law, pp. 773-800. 